
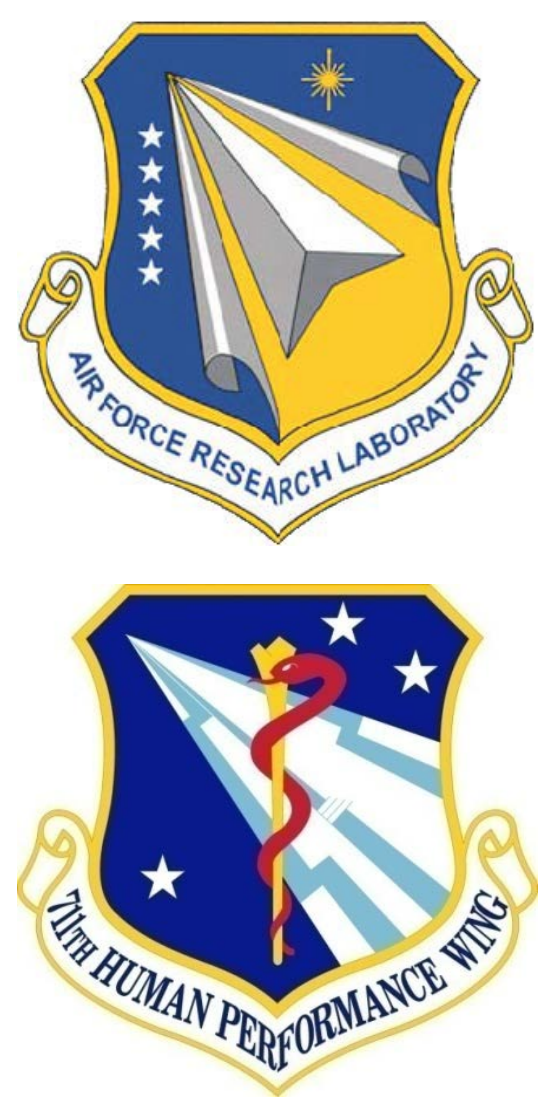

\section{AFRL-RH-WP-TR-2014-0133}

\author{
ACUTE DERMAL IRRITATION \\ STUDY IN NEW ZEALAND WHITE RABBITS: \\ FOUR ALCOHOL-TO-JET (ATJ) \\ SYNTHETIC PARAFFINIC KEROSENE (SPK) \\ ALTERNATIVE JET FUELS \\ COMPARED WITH PETROLEUM DERIVED JP-8
}

Teresa R. Sterner

Henry M. Jackson Foundation

for the Advancement of Military Medicine

Wright-Patterson AFB OH

\author{
Jonathan M. Hurley \\ WIL Research \\ Ashland $\mathrm{OH}$
}

Linda M. Shafer

Richard C. Striebich

University of Dayton Research Institute

Wright-Patterson AFB OH

David R. Mattie

Bioeffects Division

Molecular Bioeffects Branch

September 2014

Interim Report for December 2012 to May 2013
Distribution A: Approved for public release (PA); distribution unlimited. PA Case No: 88ABW2015-6081 Date Cleared: 14 January 2015
Air Force Research Laboratory $711^{\text {th }}$ Human Performance Wing Human Effectiveness Directorate Bioeffects Division Molecular Bioeffects Branch Wright-Patterson AFB OH 45433-5707 


\section{NOTICE AND SIGNATURE PAGE}

Using Government drawings, specifications, or other data included in this document for any purpose other than Government procurement does not in any way obligate the U.S. Government. The fact that the Government formulated or supplied the drawings, specifications, or other data does not license the holder or any other person or corporation; or convey any rights or permission to manufacture, use, or sell any patented invention that may relate to them.

Qualified requestors may obtain copies of this report from the Defense Technical Information Center (DTIC) (http://www.dtic.mil).

The experiments reported were conducted according to the "Guide for the Care and Use of Laboratory Animals," Institute of Laboratory Animal Resources, National Research Council.

(AFRL-RH-WP-TR - 2014 - 0133 ) has been reviewed and is approved for publication in accordance with assigned distribution statement. MATTIE.DAVID.R. R. Diglally signed by MATTIE.DAVID.R. 1230101880 1230101880 OU $=$ PKI, OU $=U S A F$, CN=MATTIE.DAVID.R.1230101880

DAVID R. MATTIE, Work Unit Manager

Molecular Bioeffects Branch

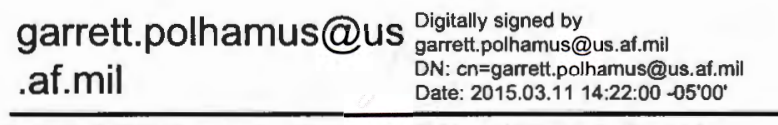

GARRETT D. POLHAMUS, DR-IV, DAF

Chief, Bioeffects Division

Human Effectiveness Directorate

711 th Human Performance Wing

Air Force Research Laboratory

This report is published in the interest of scientific and technical information exchange, and its publication does not constitute the Government's approval or disapproval of its ideas or findings. 
Public reporting burden for this collection of information is estimated to average 1 hour per response, including the time for reviewing instructions, searching existing data sources, gathering and

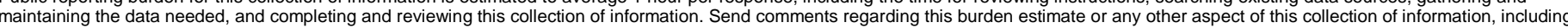

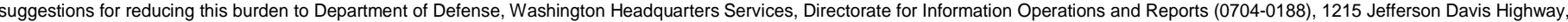

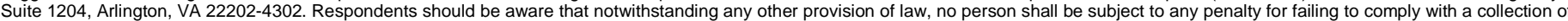
information if it does not display a currently valid OMB control number. PLEASE DO NOT RETURN YOUR FORM TO THE ABOVE ADDRESS.

\begin{tabular}{|c|l|r|r|}
\hline $\begin{array}{c}\text { 1. REPORT DATE }(D D-M M-Y Y Y Y) \\
19-09-2014\end{array}$ & 2. REPORT TYPE & 3. DATES COVERED (FrOm - To) \\
Dec 2012 - May 2013
\end{tabular}

\section{TITLE AND SUBTITLE}

Acute Dermal Irritation Study In New Zealand White Rabbits: Four Alcohol-to-Jet (ATJ) Synthetic Paraffinic Kerosene (SPK) Alternative Jet Fuels Compared With Petroleum-Derived JP-8

\section{AUTHOR(S)}

Sterner, Teresa R. ${ }^{1}$; Hurley, Jonathan M. ${ }^{2}$; Shafer, Linda M. ${ }^{3}$; Striebich, Richard C. ${ }^{3}$; Mattie, David R.*

5a. CONTRACT NUMBER

$$
\text { FA8650-10-2-6062 }
$$

\section{5b. GRANT NUMBER}

NA

5c. PROGRAM ELEMENT NUMBER

$62202 \mathrm{~F}$

5d. PROJECT NUMBER

OAFW

\section{5e. TASK NUMBER}

P0

5f. WORK UNIT NUMBER

OAFWP002/H04S

\section{PERFORMING ORGANIZATION NAME(S) AND ADDRESS(ES) \\ ${ }^{1} \mathrm{HJF}, 2729$ R St, Bldg 837, WPAFB OH 45433-5707 \\ ${ }^{2}$ WIL Research, 1407 George Rd, Ashland OH 44805-8946 \\ ${ }^{3}$ UDRI, 1790 Loop Rd, Bldg 490, WPAFB OH 45433-7251}

8. PERFORMING ORGANIZATION

\section{REPORT NUMBER}

\section{SPONSORING/MONITORING AGENCY NAME(S) AND ADDRESS(ES)}

Air Force Materiel Command*

Air Force Research Laboratory

711th Human Performance Wing

Human Effectiveness Directorate

Bioeffects Division

Molecular Bioeffects Branch

Wright-Patterson AFB OH 45433-5707
10. SPONSOR/MONITOR'S ACRONYM(S) $711 \mathrm{HPW} / \mathrm{RHDJ}$

11. SPONSORING/MONITORING AGENCY REPORT NUMBER

AFRL-RH-WP-TR-2014-0133

12. DISTRIBUTION AVAILABILITY STATEMENT A: Approved for public release (PA); distribution unlimited. (PA Case No: 88ABW-2014-6081 Date Cleared: 14 January 2015

\section{SUPPLEMENTARY NOTES}

\section{ABSTRACT}

The objective of this study was to compare the dermal irritation potential of four synthetic paraffinic kerosene (SPK) fuels produced by the alcohol to jet (ATJ) process with irritation produced by petroleum-derived JP-8. ATJ SPK alternative fuels are produced by the dehydration and refining of an isobutanol or similar alcohol feedstock. Two ATJ SPK fuels were produced by Gevo, Inc.; one was produced from petrochemical sources (Gevo ATJ SPK (non-bio)) and the other was bio-derived (Gevo ATJ SPK (bio)). The remaining two ATJ SPK fuels were produced by Swedish Biofuels AB; the original formula (SB ATJ SPK (old)) and the current version (SB ATJ SPK (new)) were both tested. A score of moderately irritating, as evaluated by the Primary Dermal Irritation Index (PDII) and Descriptive Rating, was calculated for the occluded exposures to all fuels except the Gevo ATJ SPK (non-bio), which was only slightly irritating when occluded. Slightly irritating scores were calculated for all semi-occluded exposures. All fuel exposures resulted in very slight to slight remaining erythema and/or edema through study day 14 . Normal handling of these ATJ SPK fuels by airmen, alone or in a 50:50 blend with petroleum-derived JP-8, is not expected to result in increased irritation beyond that of current JP-8 fuels.

\section{SUBJECT TERMS}

Dermal irritation, jet fuels, alternative fuels, synthetic paraffinic kerosene, JP-8, biobased/bio-based, toxicity/toxicology, alcohol-to-jet

\begin{tabular}{|c|c|c|c|c|c|}
\hline \multicolumn{3}{|c|}{$\begin{array}{l}\text { 16. SECURITY CLASSIFICATION OF: } \\
\text { U }\end{array}$} & \multirow{2}{*}{$\begin{array}{l}\text { 17. LIMITATION OF } \\
\text { ABSTRACT } \\
\text { SAR }\end{array}$} & \multirow{2}{*}{$\begin{array}{l}\text { 18. NUMBER } \\
\text { OF PAGES } \\
66\end{array}$} & \multirow{2}{*}{$\begin{array}{l}\text { 19a. NAME OF RESPONSIBLE PERSON } \\
\text { David R. Mattie } \\
\begin{array}{l}\text { 19b. TELEPONE NUMBER (Include area code) } \\
\text { NA }\end{array}\end{array}$} \\
\hline $\begin{array}{l}\text { a. REPORT } \\
\text { U }\end{array}$ & \begin{tabular}{|l} 
b. ABSTRACT \\
U
\end{tabular} & $\begin{array}{l}\text { c. THIS PAGE } \\
\text { U }\end{array}$ & & & \\
\hline
\end{tabular}
$\mathrm{U}$ U 
THIS PAGE INTENTIONALLY LEFT BLANK. 


\section{TABLE OF CONTENTS}

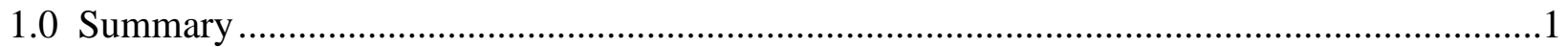

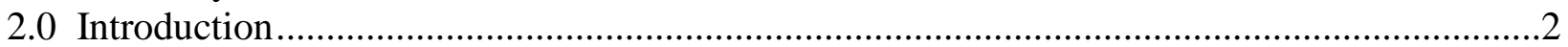

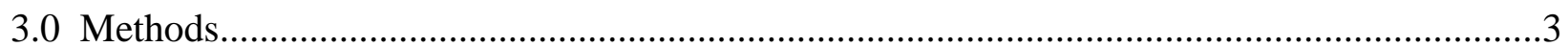

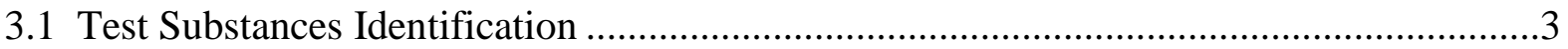

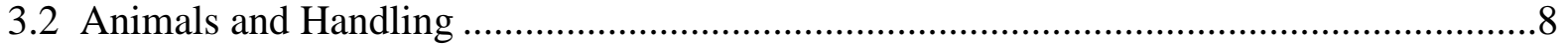

3.3 Topical Administration of Test Fuels ....................................................................9

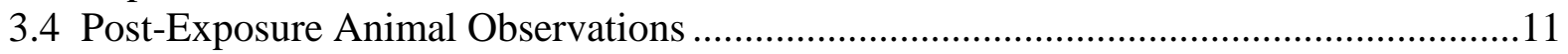

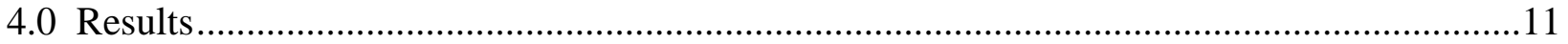

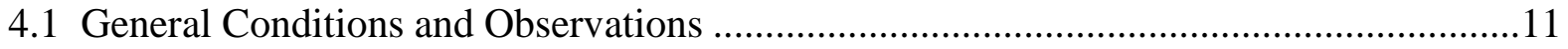

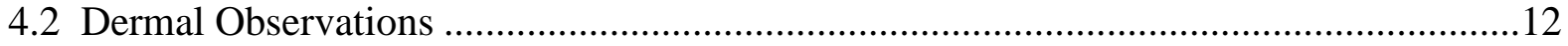

4.3 Compliance, Quality Assurance and Data Retention.................................................14

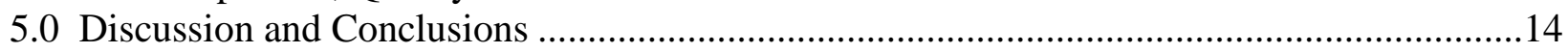

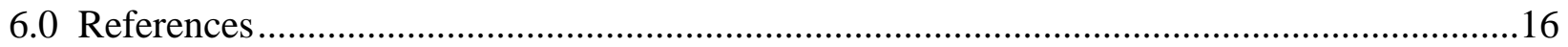

Appendix A. Comprehensive Two-Dimensional Gas Chromatography Analysis and

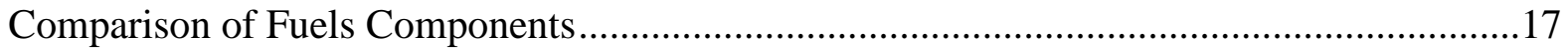

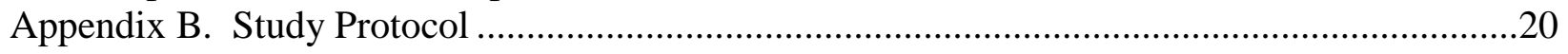

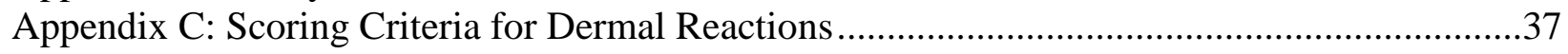

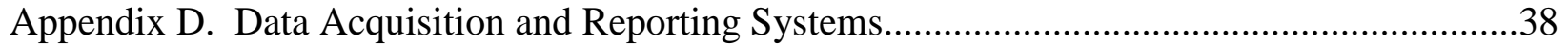

Appendix E. Animal Room Environmental Conditions .......................................................39

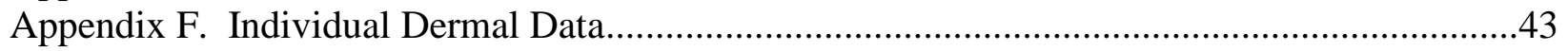

Appendix G. Compliance, Report Approval And Quality Assurance Statements ......................53

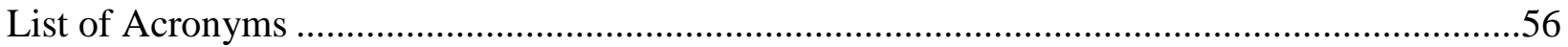




\section{LIST OF FIGURES}

Figure 1. GC x GC Chromatogram of Petroleum-Derived JP-8 (POSF 4658) ............................5

Figure 2. GC x GC Chromatogram of Gevo ATJ SPK (non-bio) ..............................................5

Figure 3. GC x GC Chromatogram of Gevo ATJ SPK (bio) ..................................................6

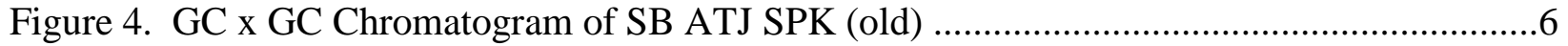

Figure 5. GC x GC Chromatogram of SB ATJ SPK (new) ..................................................

Figure 6. Dermal Dosing Sites on New Zealand White Rabbits .............................................10 


\section{LIST OF TABLES}

Table 1. Test Substance Identification and Description .....

Table 2. Summary Comprehensive Two-Dimensional Gas Chromatography Component

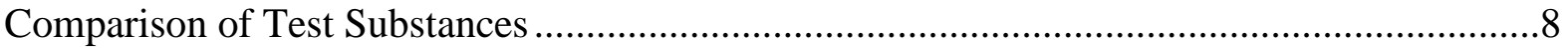

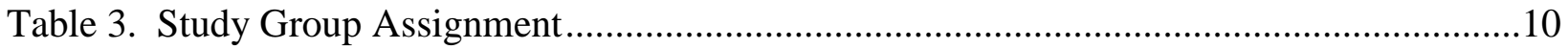

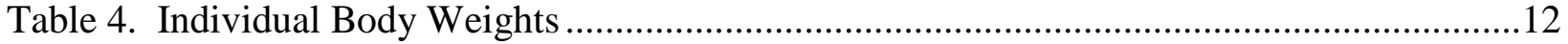

Table 5. Summary Table of Dermal Finding Descriptions during the First 72 hours and on

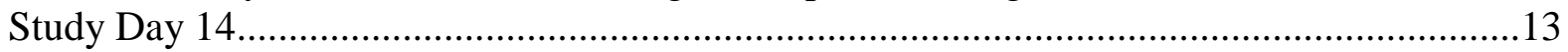

Table 6. Summary Table of PDII and Descriptive Rating for Dermal Irritation .........................14 
THIS PAGE INTENTIONALLY LEFT BLANK. 


\section{PREFACE}

Funding for this project was provided through the former Alternative Fuels Certification Office (AFLCMC/WNN) for the Gevo fuels and the DOD Coalition Warfare Program for the Swedish Biofuels. This research was conducted under contract FA8650-10-2-6062 with the Henry M. Jackson Foundation for the Advancement of Military Medicine (HJF). The program manager for the HJF contract was David R. Mattie, PhD (711 HPW/RHDJ), who was also the technical manager for this project.

The dermal irritation study protocol was designed to be in general compliance with the U.S. Environmental Protection Agency (EPA) Office of Prevention, Pesticides and Toxic Substances (OPPTS) Guideline 870.2500 (1998) and the Organisation for Economic Co-operation and Development (OECD) Guidelines for Testing of Chemicals, Section 404 (2002). The study was conducted in compliance with 40 CFR Part 792, Good Laboratory Practice Standards (GLP).

The study protocol was approved by the Air Force Surgeon General's Office of Research Oversight and Compliance (protocol number FWR-2010-0002A, Acute Dermal Irritation Study of Alternative and Bio-Based Jet Fuels in New Zealand White Rabbits, Oryctolagus cuniculus) and the WIL Research Laboratories, LLC, Animal Care and Use Committee (protocol number WIL-773003). The study was conducted in a facility accredited by the Association for the Assessment and Accreditation of Laboratory Animal Care, International, in accordance with the Guide for the Care and Use of Laboratory Animals (NRC, 2011).

The authors would like to acknowledge J. Tim Edwards, PhD of the Fuels and Energy Branch (AFRL/RQTF, WPAFB OH) for providing the test fuels and reviewing the analyses of these complex mixtures. 
THIS PAGE INTENTIONALLY LEFT BLANK. 


\subsection{SUMMARY}

The objective of this study was to compare the dermal irritation potential of jet fuels of interest to the U.S. Air Force. Four synthetic paraffinic kerosene (SPK) fuels produced by the alcohol to jet (ATJ) process were compared to petroleum-derived JP-8 (POSF 4658+). The U.S. Air Force is investigating ATJ SPK fuels for use in a 50:50 blend with petroleum-derived JP-8. All fuels were identified by a commercial name and by the POSF log book number provided by the Air Force Research Laboratory Fuels and Energy Branch (AFRL/RQTF, formerly of the Air Force Wright Aeronautical Laboratories (AFWAL/POSF), Wright-Patterson AFB OH). All fuels contained the standard JP-8 additive package. Use of commercial names and products does not constitute endorsement of these products by the U.S. Air Force.

ATJ SPK fuels are produced by the dehydration and refining of an isobutanol or similar mixed alcohol feedstock. Alcohol sources may be non-renewable (from petrochemical sources) or renewable (from the fermentation of sugars provided through plant oils and animal fats). Two ATJ SPK fuels were produced by Gevo, Inc. (Englewood CO); one was produced from petrochemical sources (Gevo ATJ SPK (non-bio), POSF 7695 (alone), POSF 7699 with additives) and the other was bio-derived (Gevo ATJ SPK (bio), POSF 9641 (alone), POSF 10021 with additives). The remaining two ATJ SPK fuels were produced by Swedish Biofuels AB (Stockholm); the original formula (SB ATJ SPK (old), POSF 5668 (alone), POSF 10234 with additives) and the current version (SB ATJ SPK (new), POSF 7633 (alone), POSF 8452 with additives) were both tested.

Doses $(0.5 \mathrm{~mL})$ of each fuel were applied to separate areas of clipped, unabraded skin on the backs of New Zealand white rabbits. Five application sites were used per rabbit. Groups consisted of three rabbits; two groups allowed for 4-hour occluded or semi-occluded exposures. Application sites were evaluated in accordance with the method of Draize (1965) and in compliance with the U.S. Environmental Protection Agency (EPA, 1998) and Organisation for Economic Co-operation and Development (OECD, 2002) at approximately 30 to 60 minutes and 24, 48 and 72 hours after patch removal, and on study days 4, 7 and 14, if irritation persisted.

There were no deaths or remarkable body weight changes noted during the study. Dermal findings during the study consisted of very slight to moderate erythema, as well as very slight to moderate edema. All fuel exposures resulted in very slight to slight remaining erythema and/or edema through study day 14. A score of moderately irritating, as evaluated by the Primary Dermal Irritation Index (PDII) and Descriptive Rating, was calculated for the occluded exposures to all fuels except the Gevo ATJ SPK (non-bio), which was slightly irritating when occluded. Slightly irritating scores were calculated for all semi-occluded exposures. Normal handling of these ATJ SPK fuels by Airmen, alone or in mixture with petroleum-derived JP-8, is not expected to result in increased irritation beyond that of current JP-8 fuels. 


\subsection{INTRODUCTION}

The pursuit of alternative fuels in the Department of Defense (DOD) is policy under the FY2012 National Defense Authorization Act. Per the Act, alternative fuels must be drop-in ready (require no equipment modification), be cost-competitive, be available in quantity, be made from non-food crops and have emissions comparable to or less than petroleum-derived fuels. The U.S. Air Force (USAF) set a goal to be able to fly and drive on 50 percent petroleum/alternative blends by 2016 (Blakeley, 2012). Fuels being certified by the USAF include those produced through a process called alcohol to jet (ATJ). ATJ synthetic paraffinic kerosene (SPK) fuels are produced by the dehydration and refining of an alcohol feedstock. Feedstock sources may be non-renewable (from petrochemical sources) or renewable (from the fermentation of sugars provided through plant oils and animal fats). The U.S. Air Force is investigating ATJ SPK fuels for use in a 50:50 blend with petroleum-derived JP-8. As each alternative fuel's composition is different from JP-8, potential health effects from fuel exposure must be considered during fuel development.

The objective of this study was to compare the dermal irritation potential of jet fuels of interest to the USAF. All fuels were identified by a commercial name and by the POSF log book number provided by the Air Force Research Laboratory Fuels and Energy Branch (AFRL/RQTF, formerly of the Air Force Wright Aeronautical Laboratories (AFWAL/POSF), Wright-Patterson AFB OH). All fuels contained the standard JP-8 additive package. Use of commercial names and products does not constitute endorsement of these products by the USAF but does reflect the variety of jet fuels to which Airmen may be exposed, now or in the future.

Four SPK fuels produced by the ATJ process were compared to petroleum-derived JP-8 (POSF 4658+). Petroleum-derived JP-8 was included as a "positive" control with which to compare dermal responses from other fuels. Two ATJ SPK fuels were produced by Gevo, Inc. (Englewood CO). The first, Gevo ATJ SPK (non-bio) (POSF 7695 (alone), POSF 7699 with additives) was produced from an isobutanol derived from petrochemical sources and is therefore a non-renewable fuel. The second, Gevo ATJ SPK (bio) (POSF 9641 (alone), POSF 10021 with additives) was produced from a biologically derived isobutanol feedstock. The Gevo proprietary process utilizes a yeast biocatalyst to ferment sugars from a mixed biological source feedstock into isobutanol. Biological sources for the Gevo feedstock currently include grains (corn, wheat, sorghum, barley, etc.) and sugarcane but will be expanded to cellulosic feedstocks (switchgrass, waste wood, corn cob/stalk pulp, sugarcane waste) in the near future (Gevo, 2014).

The remaining two ATJ SPK fuels were produced by Swedish Biofuels AB (Stockholm). These fuels were developed through an international agreement and funded by the U.S. Defense Advanced Research Projects Agency (DARPA) (Swedish Biofuels, 2014a). The Swedish Biofuels process ferments sugars from grains or wood to a mixture of alcohols containing 2 to 5 carbon atoms. This mixture is then synthesized into hydrocarbons in the JP-8 range (Swedish Biofuels, 2014b). The original formula, SB ATJ SPK (old) (POSF 5668 (alone); 10234 with additives) was provided for testing in 2010. The aromatic content of this fuel consists of primarily one component, trimethylbenzene. The current version (SB ATJ SPK (new), POSF 7633 (alone); 8452 with additives) was provided in 2012. The updated version is more 
chemically similar to JP-8, as the aromatic portion contains several alkylbenzene constituents instead of mostly one. Both versions were tested for dermal irritation potential.

One fuel in the current study, SB ATJ SPK (old), has been evaluated previously for dermal irritation potential, as part of a study of 10 synthetic fuels produced by different chemical production processes. This fuel was determined to be slightly irritating to the skin, in both occluded and semi-occluded exposures, using the same methods as the study herein (Sterner et al., 2014a).

\subsection{METHODS}

\subsection{Test Substances Identification}

WIL Labs received the test substances from 711 HPW/RHDJ, Wright-Patterson Air Force Base (AFB) OH, on 6 Feb 2013. WIL Labs then performed the dermal irritation tests. Received samples are listed in Table 1, which contains the test substances identification and visual appearance description. Test substances are identified by two POSF log book numbers (one for the fuel alone and one for the fuel with the additive package) as well as WIL identification numbers (Table 1). Purity and stability data are maintained by the USAF Air Force Research Laboratory (AFRL) Fuels and Energy Branch (AFRL/RQTF, Wright-Patterson AFB OH).

The test substances were stored at room temperature in a flame cabinet and were considered stable under these conditions. Prior to use, the original container of each test substance was inverted or swirled to ensure a homogeneous mixture. A reserve sample of each test substance was collected and stored in the WIL Archives. 
Table 1. Test Substance Identification and Description

\begin{tabular}{|c|c|c|c|c|c|}
\hline $\begin{array}{c}\text { Test } \\
\text { Substance }\end{array}$ & Identification & $\begin{array}{c}\text { POSF } \\
\text { (alone) }\end{array}$ & $\begin{array}{c}\text { POSF } \\
\text { (with } \\
\text { additives) }\end{array}$ & WIL ID \# & $\begin{array}{c}\text { Physical } \\
\text { Description }\end{array}$ \\
\hline 1 & JP-8 & 4658 & $4658+$ & $13003 \mathrm{~B}$ & $\begin{array}{c}\text { Clear, very light } \\
\text { yellow liquid }\end{array}$ \\
\hline 2 & $\begin{array}{c}\text { Gevo ATJ SPK } \\
\text { petrochemically derived } \\
\text { (Gevo ATJ SPK (non-bio)) }\end{array}$ & 7695 & 7699 & $13003 \mathrm{C}$ & $\begin{array}{c}\text { Clear, colorless } \\
\text { liquid }\end{array}$ \\
\hline 3 & $\begin{array}{c}\text { Gevo ATJ SPK } \\
\text { biologically derived } \\
\text { (Gevo ATJ SPK (bio)) }\end{array}$ & 9641 & 10021 & $13005 \mathrm{~B}$ & $\begin{array}{c}\text { Clear, colorless } \\
\text { liquid }\end{array}$ \\
\hline 4 & $\begin{array}{c}\text { Swedish Biofuel } \\
\text { original formulation } \\
\text { (SB ATJ SPK (old)) }\end{array}$ & 5668 & 10234 & $13003 \mathrm{D}$ & $\begin{array}{c}\text { Clear, colorless } \\
\text { liquid }\end{array}$ \\
\hline 5 & $\begin{array}{c}\text { Swedish Biofuel } \\
\text { current formulation } \\
\text { (SB ATJ SPK (new) }\end{array}$ & 7633 & 8452 & $13005 \mathrm{~A}$ & $\begin{array}{c}\text { Clear, colorless } \\
\text { liquid }\end{array}$ \\
\hline
\end{tabular}

Notes: POSF: AFRL Fuels and Energy Branch log book numbers; NA: not applicable; WIL ID \#: identification numbers maintained by WIL Research

Comprehensive two-dimensional gas chromatography (GC x GC) was used to characterize each fuel (Striebich et al., 2014). Chromatograms of each fuel are shown in Figures 1 through 5. A summary of the GC x GC analysis of these fuels is provided in Table 2. A more complete version of the GC x GC analysis for each fuel can be found in Appendix A. 


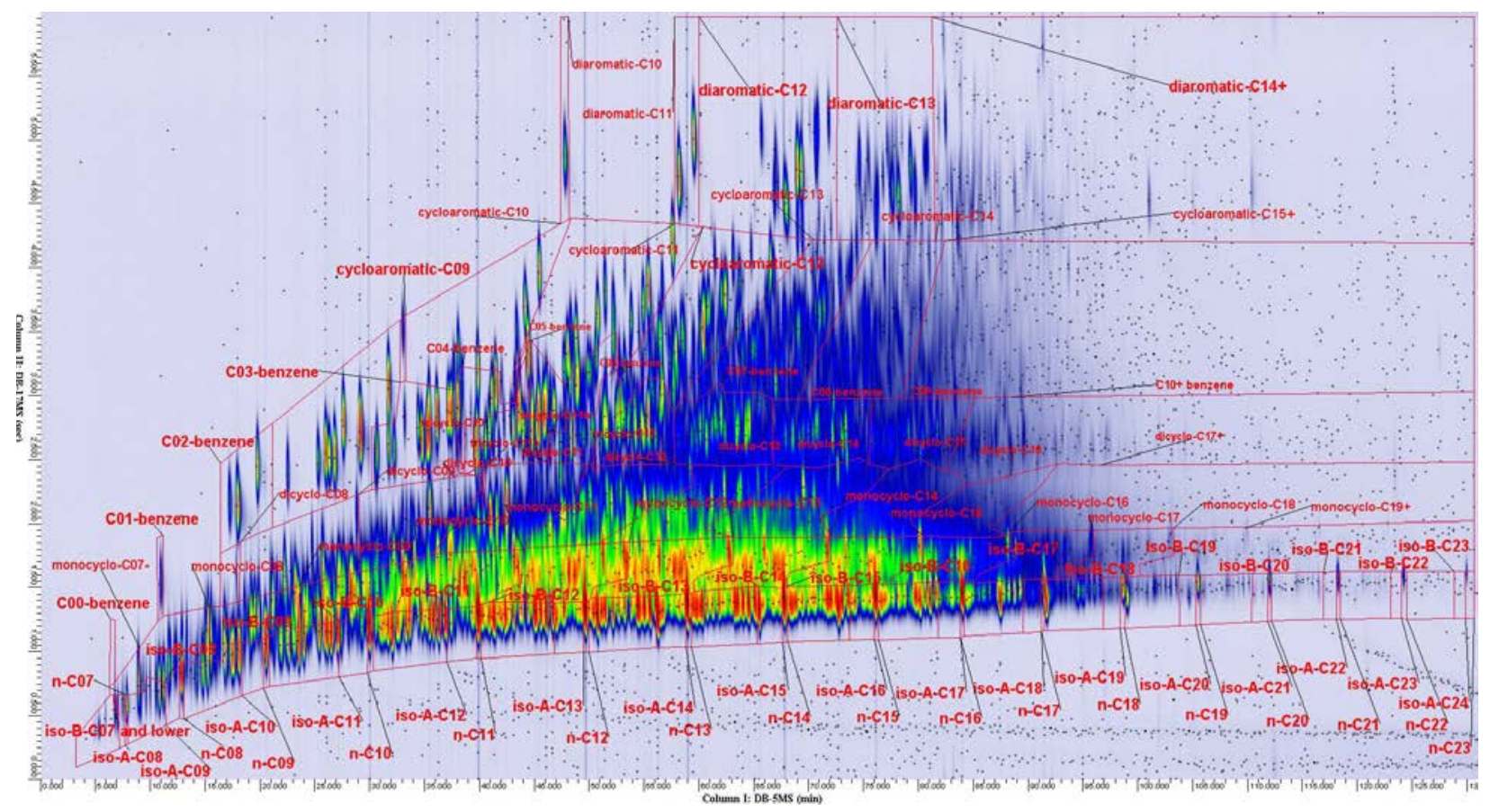

Figure 1. GC x GC Chromatogram of Petroleum-Derived JP-8 (POSF 4658)

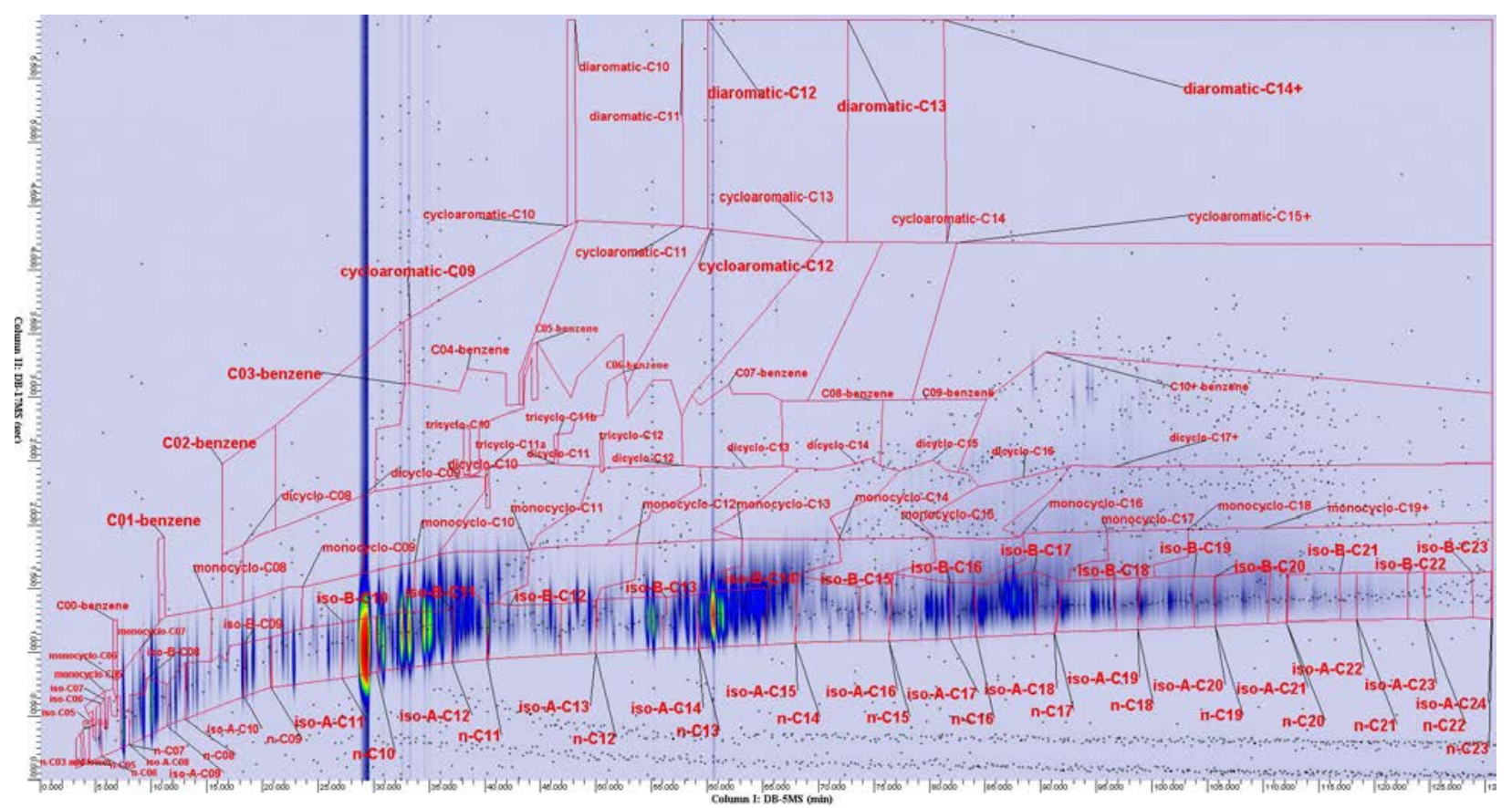

Figure 2. GC x GC Chromatogram of Gevo ATJ SPK (non-bio) 


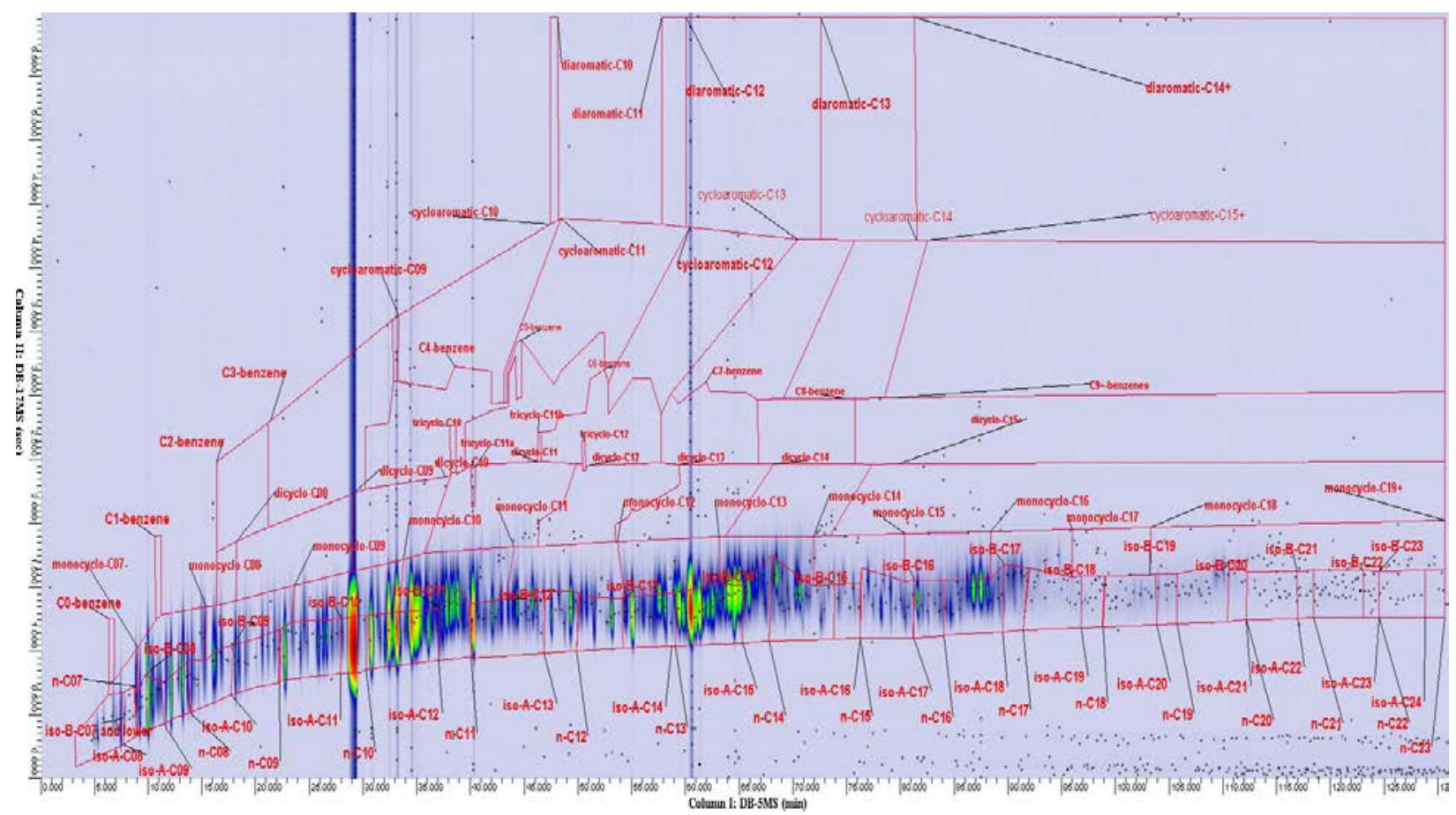

Figure 3. GC x GC Chromatogram of Gevo ATJ SPK (bio)

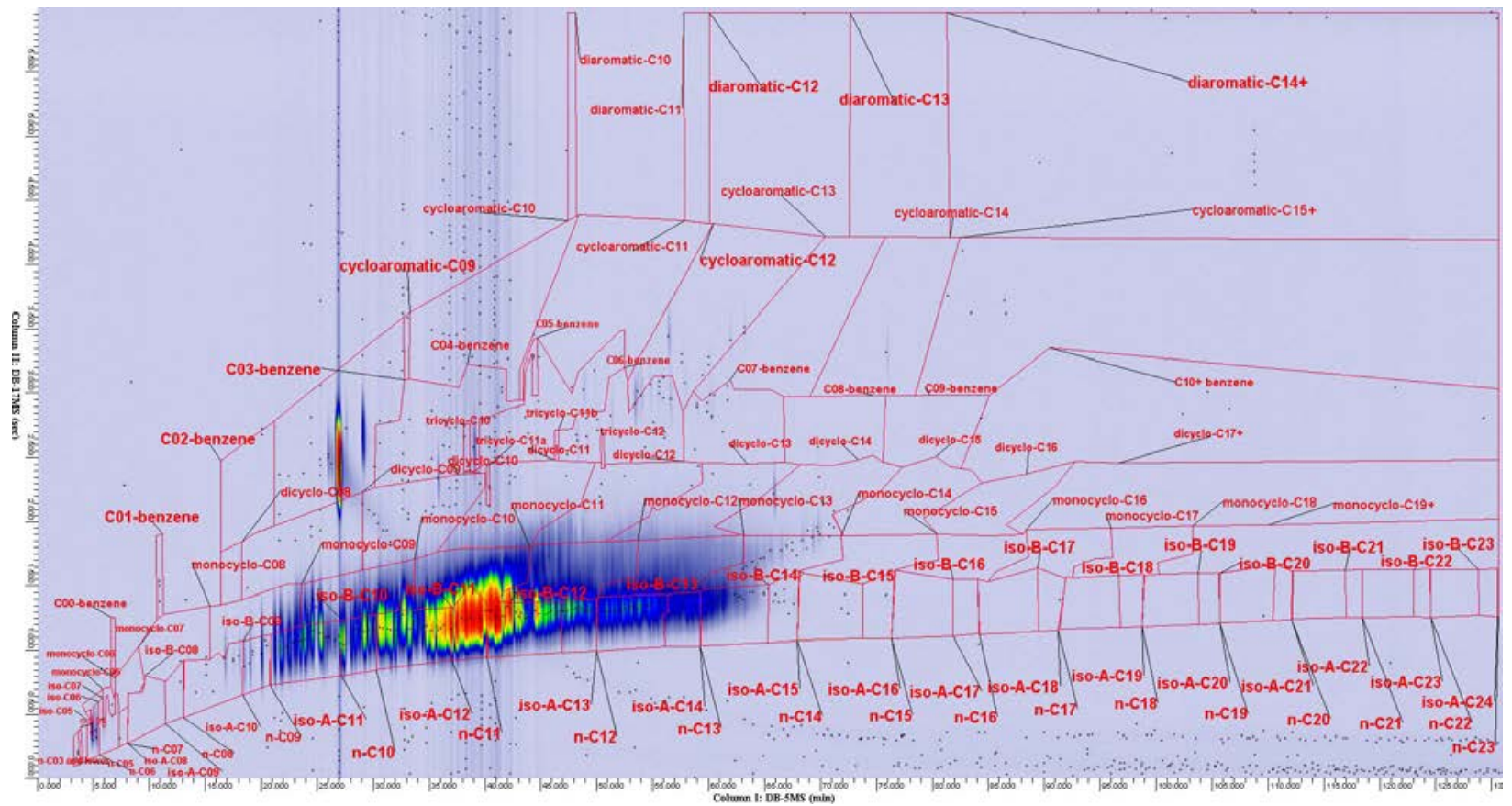

Figure 4. GC x GC Chromatogram of SB ATJ SPK (old) 


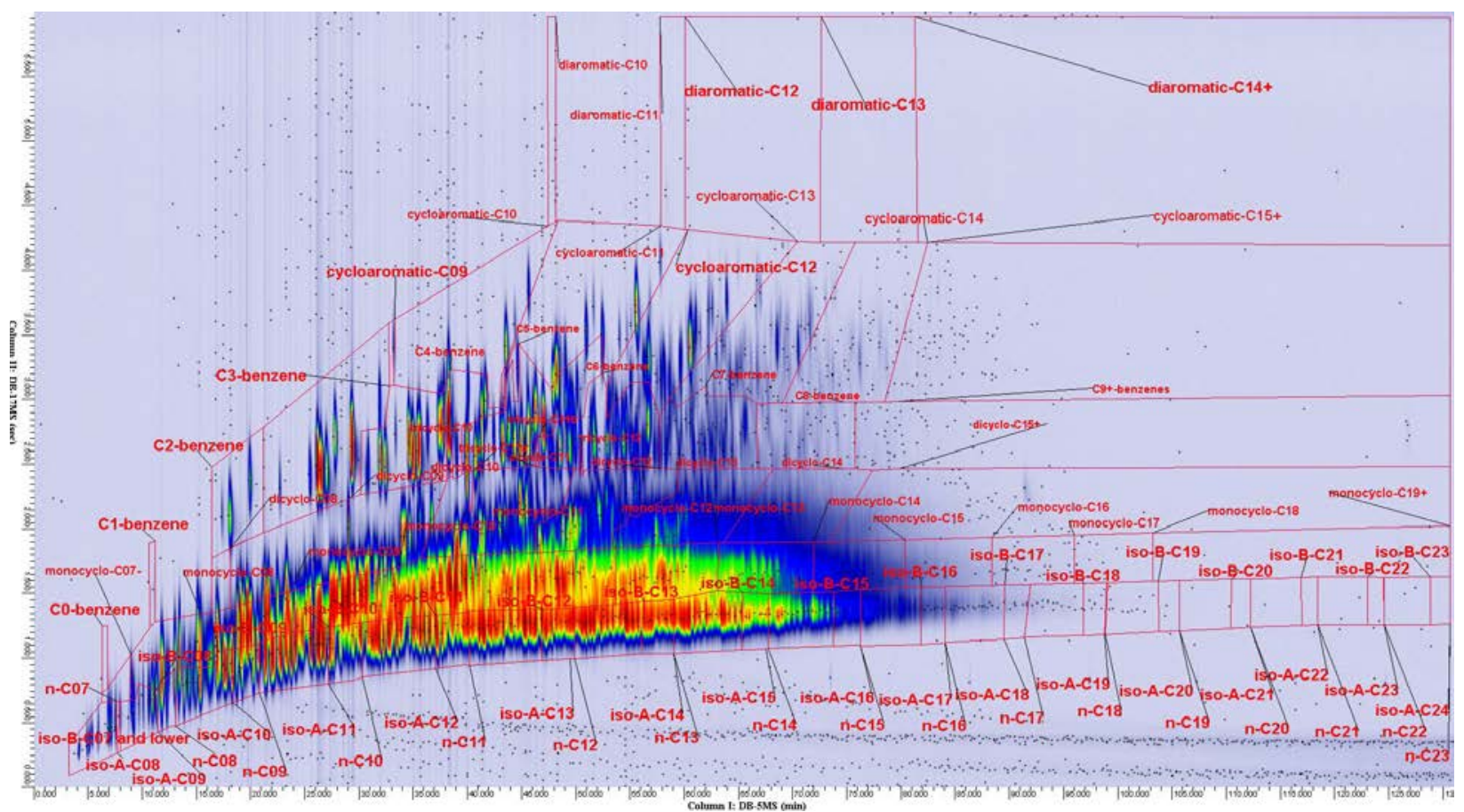

Figure 5. GC x GC Chromatogram of SB ATJ SPK (new) 
Table 2. Summary Comprehensive Two-Dimensional Gas Chromatography Component Comparison of Test Substances

\begin{tabular}{|c|c|c|c|c|c|}
\hline Fuel & JP-8 & $\begin{array}{c}\text { Gevo } \\
\text { ATJ SPK } \\
\text { (non-bio) }\end{array}$ & $\begin{array}{c}\text { Gevo } \\
\text { ATJ SPK } \\
\text { (bio) } \\
\end{array}$ & $\begin{array}{c}\text { SB } \\
\text { ATJ SPK } \\
\text { (old) }\end{array}$ & $\begin{array}{c}\text { SB } \\
\text { ATJ SPK } \\
\text { (new) }\end{array}$ \\
\hline POSF* & 4658 & 7695 & 9641 & 5668 & 7633 \\
\hline \multicolumn{6}{|l|}{ AROMATICS } \\
\hline Total Alkylbenzenes & 13.69 & 0.24 & $<0.01$ & 13.16 & 10.47 \\
\hline Total Alkylnaphthalenes & 1.76 & $<0.01$ & $<0.01$ & $<0.01$ & $<0.01$ \\
\hline Total Cycloaromatics & 5.79 & 0.01 & $<0.01$ & 0.02 & 1.71 \\
\hline Total Aromatics & 21.24 & 0.25 & 0.01 & 13.18 & 12.18 \\
\hline \multicolumn{6}{|l|}{ ALIPHATICS } \\
\hline Total iso-Paraffins & 31.34 & 98.27 & 99.43 & 86.30 & 44.14 \\
\hline Total n-Paraffins & 19.00 & 0.02 & 0.02 & 0.05 & 0.66 \\
\hline Total Cycloparaffins & 28.42 & 1.47 & 0.54 & 0.47 & 43.00 \\
\hline Total Aliphatics & 78.76 & 99.76 & 99.99 & 86.82 & 87.80 \\
\hline TOTAL & 100.00 & 100.01 & 100.00 & 100.00 & 99.98 \\
\hline
\end{tabular}

Note: Component values given in mass percent. *Component analysis is performed on the fuel prior to addition of additives.

\subsection{Animals and Handling}

The complete animal use protocol for this study is found in Appendix B. Male New Zealand White albino rabbits were used as the test system for this study. This animal model is generally recognized as appropriate for acute dermal irritation studies. The experimental design used the procedures and standards required by the current federal and international test guidelines. The number of animals selected (three per group) was the minimum required to satisfy regulatory guidelines. The rabbits were young adults (at least 5 months of age) at the initiation of dose administration.

New Zealand White albino rabbits utilized for this study were received in good health from Covance Research Products, Inc. (Denver PA) on 19 October 2012 (animal numbers 9855, 9852, 9847 and 9859), or Covance Research Products, Inc. (Greenfield IN) on 22 February 2013 (animal numbers 7509 and 7510). The rabbits were inspected by a qualified technician upon receipt. The animals were weighed and uniquely identified with a subcutaneous BioMedic Data Systems, Inc. (BMDS, Seaford DE) microchip implanted in the dorsoscapular area. The rabbits were acclimated to laboratory conditions for a minimum of 18 days. During this period, each animal was observed twice daily for mortality, morbidity and changes in general appearance or behavior.

Upon arrival, all animals were housed in individual stainless steel cages. The animals were maintained by the animal husbandry staff of WIL Research in accordance with standard 
operating procedures (SOPs). The animal facilities at WIL Research are accredited by the Association for Assessment and Accreditation of Laboratory Animal Care (AAALAC) International. Environmental enrichment devices were provided to all animals as appropriate.

The basal diet used in this study, PMI Nutrition International, LLC (St. Louis MO) Certified High Fiber Rabbit LabDiet ${ }^{\circledR}$ 5325, is a certified feed with appropriate analyses performed by the manufacturer and provided to WIL Research. Municipal water supplying the facility was analyzed for contaminants according to WIL Research SOPs. The results of the diet and water analyses are maintained at WIL Research. No contaminants were present in animal feed or water at concentrations sufficient to interfere with the objectives of this study. The basal diet was provided at approximately $150 \mathrm{~g}$ /day while municipal water, delivered by an automatic watering system, was provided ad libitum throughout the acclimation period and during the study.

All animals were housed throughout the acclimation period and during the study in an environmentally controlled room. The room temperature and humidity controls were set to maintain environmental conditions of $66 \pm 5^{\circ} \mathrm{F}\left(19 \pm 3^{\circ} \mathrm{C}\right)$ and $50 \pm 20$ percent relative humidity. Room temperature and relative humidity data were monitored continuously and were scheduled for automatic collection on an hourly basis. Fluorescent lighting provided illumination for a 12 hour light (0600 hours to 1800 hours) photoperiod, followed by a 12 hour dark period. Air handling units were set to provide a minimum of 10 fresh air changes per hour.

\subsection{Topical Administration of Test Fuels}

The selected route of administration for this study was direct application to clipped, unabraded skin (dermal). This route is standard for assessment of local dermal irritative potential. This study was intended to provide information on the health hazards likely to arise from a short-term exposure to these jet fuels by the dermal route. The experimental design used the procedures and standards in compliance with the U.S. Environmental Protection Agency (U.S. EPA, 1998) and the Organisation for Economic Co-operation and Development (OECD, 2002).

Animals used in the study were selected from available stock based upon health and body weight. There were two groups of three rabbits. On each rabbit, five unabraded sites were utilized (from six available test sites). Animals in Group 1 received a single occluded exposure to each of the five jet fuels. Animals in Group 2 received a single semi-occluded exposure to each of the five jet fuels. Table 3 presents the study group assignment. 
Table 3. Study Group Assignment

\begin{tabular}{|c|c|c|c|c|c|}
\hline $\begin{array}{c}\text { Group } \\
\text { Number }\end{array}$ & $\begin{array}{c}\text { Test } \\
\text { Substance }\end{array}$ & $\begin{array}{c}\text { Dose Volume } \\
(\mathbf{m L})\end{array}$ & $\begin{array}{c}\text { Exposure } \\
\text { Method* }\end{array}$ & $\begin{array}{c}\text { Number of } \\
\text { Animals }\end{array}$ & $\begin{array}{c}\text { Animal } \\
\text { Numbers }\end{array}$ \\
\hline 1 & $1,2,3,4,5$ & 0.5 & Occluded & 3 & 9847 \\
& & & & & 9852 \\
& $1,2,3,4,5$ & 0.5 & Semi-occluded & 3 & 7509 \\
\hline 2 & & & & & 7510 \\
& & & & & 9859 \\
\hline
\end{tabular}

Note: *unabraded skin

On the day prior to dosing, the hair was removed from the backs and flanks of the rabbits using an electric clipper. Five application sites were utilized for dosing, as depicted in Figure 6; only sites A through E were used for this study. Fuels were assigned a site in rotation (first fuel applied to site A on first rabbit, B on second rabbit, etc.). Adjacent areas of untreated skin served as a control for each test site. Each 0.5-mL dose was applied to an area of skin approximately $2.5 \mathrm{~cm} \times 2.5 \mathrm{~cm}$ under a two-ply gauze patch secured in place with Micropore ${ }^{\mathrm{TM}}$ tape (3M, St. Paul MN). For animals in the occluded exposure groups, the trunk of the animal was wrapped with plastic wrap (over the gauze patches) to occlude the test site. The trunk of animals in both the occluded and semi-occluded groups was then wrapped with a gauze binder secured with Dermiform ${ }^{\circledR}$ tape (Johnson and Johnson, New Brunswick NJ). Plastic restraint collars were applied to the animals to prevent ingestion of the test substance and/or bandages. After four hours of exposure (actual exposure times ranging from approximately 4 hours 1 minute to 4 hours 5 minutes), the collars and bandages were removed and each of the sites was wiped with a new disposable paper towel moistened with deionized water.

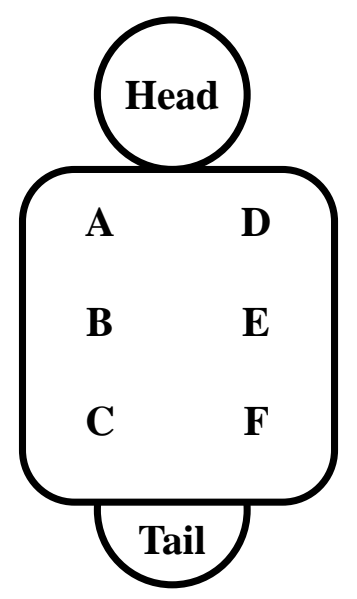

Figure 6. Dermal Dosing Sites on New Zealand White Rabbits 


\subsection{Post-Exposure Animal Observations}

The rabbits were observed twice daily, once in the morning and once in the afternoon, for mortality and morbidity. All animals received detailed physical examinations on the day of dosing. Body weights were obtained and recorded on study day 0 (initiation) and at each rabbit's termination from the study (study day 15).

The application sites were observed for erythema, edema and other dermal findings approximately 30 to 60 minutes and 24, 48 and 72 hours after patch removal, and, if irritation persisted, on study days 4, 7 and 14. Dermal irritation was graded in accordance with the method of Draize (1965), as detailed in Appendix C. The areas of application were clipped free of hair a minimum of one hour prior to scoring and as needed during the study, to facilitate accurate dermal observations.

Primary Dermal Irritation Index (PDII) was calculated from scores recorded at 30 to 60 minutes and at 24, 48 and 72 hours after patch removal. The mean scores for erythema and edema were calculated separately to the nearest tenth and added together. Based on this value, the grading system in Appendix C was used to arrive at the PDII descriptive rating.

All animal observations were hand-recorded and then reported utilizing the WIL in-house data acquisitions and reporting systems detailed in Appendix D. Other data, including the dispensing of the test article when dosing, and facility temperature and humidity readings, were recorded electronically in the systems listed in Appendix D. Following study termination, the rabbits were euthanized in accordance with current American Veterinary Medical Association (AVMA) guidelines (AVMA, 2007).

\subsection{RESULTS}

\subsection{General Conditions and Observations}

Animal room conditions are summarized in Appendix E. Mean daily temperatures ranged from $65.2^{\circ} \mathrm{F}$ to $65.6^{\circ} \mathrm{F}\left(18.4^{\circ} \mathrm{C}\right.$ to $\left.18.7^{\circ} \mathrm{C}\right)$ and mean daily relative humidity ranged from 44.4 to 47.4 percent during the study.

There were no deaths during the study. Body weight values ranged from $2619 \mathrm{~g}$ to $4204 \mathrm{~g}$ at the initiation of dosing. Slight body weight losses were noted in some animals in various groups. Slight fluctuations in body weight are commonly observed in animals maintained on a restricted diet. Individual body weights are detailed in Table 4. 
Table 4. Individual Body Weights

\begin{tabular}{|c|c|c|c|c|}
\hline $\begin{array}{c}\text { Group } \\
\text { Number }\end{array}$ & $\begin{array}{c}\text { Test } \\
\text { Substance }\end{array}$ & $\begin{array}{c}\text { Animal } \\
\text { Number }\end{array}$ & $\begin{array}{c}\text { Day 0 } \\
\text { Weight (g) }\end{array}$ & $\begin{array}{c}\text { Day 15 } \\
\text { Termination } \\
\text { Weight (g) }\end{array}$ \\
\hline \multirow{2}{*}{$\begin{array}{c}1 \\
\text { Occluded }\end{array}$} & \multirow{2}{*}{ 1, 2, 3, 4, 5 } & 9855 & 3834.5 & 3832.0 \\
\cline { 3 - 5 } & & 9852 & 3708.0 & 3712.1 \\
\cline { 3 - 5 } $\begin{array}{c}2 \\
\text { Semi-occluded }\end{array}$ & \multirow{2}{*}{ 1, 2, 3, 4, 5 } & 9847 & 3786.7 & 3745.2 \\
\cline { 3 - 5 } & & 7859 & 4203.6 & 4146.5 \\
\cline { 3 - 5 } & 7510 & 2797.9 & 2960.0 \\
\hline
\end{tabular}

\subsection{Dermal Observations}

Dermal findings ranged from very slight (grade 1), slight (grade 2) to moderate (grade 3) erythema and/or edema (Table 5). Findings persisted through study day 14. There was no significant difference in irritation noted between the baseline fuel (JP-8) and the four bio-based jet fuels when administered dermally. All were moderately irritating when exposed occluded and slightly irritating when exposed semi-occluded with the exception of occluded Gevo ATJ SPK (non-bio), which was slightly irritating when exposed using either method. 
Table 5. Summary Table of Dermal Finding Descriptions during the First 72 hours and on Study Day 14

\begin{tabular}{|c|c|c|c|c|}
\hline Finding & Erythema & Edema & Erythema & Edema \\
\hline Study Stage & First 72 Hours & First 72 Hours & Study Day 14 & Study Day 14 \\
\hline Occluded Exposures & $\begin{array}{c}\text { very slight } \\
\text { to slight }\end{array}$ & moderate & $\begin{array}{c}\text { very slight } \\
\text { to slight }\end{array}$ & very slight \\
\hline Gevo ATJ SPK (non-bio) & $\begin{array}{c}\text { very slight } \\
\text { to slight }\end{array}$ & not found & $\begin{array}{c}\text { very slight } \\
\text { to slight }\end{array}$ & very slight \\
\hline Gevo ATJ SPK (bio) & $\begin{array}{c}\text { very slight } \\
\text { to slight }\end{array}$ & $\begin{array}{c}\text { very slight } \\
\text { to moderate }\end{array}$ & $\begin{array}{c}\text { very slight } \\
\text { to slight }\end{array}$ & very slight \\
\hline SB ATJ SPK (old) & $\begin{array}{c}\text { very slight } \\
\text { to slight }\end{array}$ & $\begin{array}{c}\text { very slight } \\
\text { to slight }\end{array}$ & $\begin{array}{c}\text { very slight } \\
\text { to slight }\end{array}$ & very slight \\
\hline SB ATJ SPK (new) & $\begin{array}{c}\text { very slight } \\
\text { to slight }\end{array}$ & $\begin{array}{c}\text { slight to } \\
\text { moderate }\end{array}$ & slight & very slight \\
\hline Semi-Occluded Exposures & \multicolumn{2}{|l|}{$\begin{array}{c}\text { very slight } \\
\text { to slight }\end{array}$} & not found \\
\hline JP-8 & $\begin{array}{c}\text { very slight } \\
\text { to slight }\end{array}$ & very slight & very slight & not found \\
\hline Gevo ATJ SPK (non-bio) & $\begin{array}{c}\text { very slight } \\
\text { to slight }\end{array}$ & not found & not found \\
\hline Gevo ATJ SPK (bio) & $\begin{array}{c}\text { very slight } \\
\text { to slight }\end{array}$ & not found & very slight & not found \\
\hline SB ATJ SPK (old) & $\begin{array}{c}\text { very slight to } \\
\text { slight }\end{array}$ & not found & very slight & not found \\
\hline SB ATJ SPK (new) & $\begin{array}{c}\text { very slight to } \\
\text { slight }\end{array}$ & very slight & very slight & \\
\hline
\end{tabular}

Numerical scores were assigned to the dermal findings recorded at 30 to 60 minutes and at 24, 48 and 72 hours. The mean scores for erythema and edema were calculated separately to the nearest tenth and added together. The PDII was then calculated for each fuel (Table 6). Based on this value, the grading system in Appendix $\mathrm{C}$ was used to arrive at the PDII descriptive rating. Individual score data are found in Appendix F. Application site assignments for each fuel/rabbit are also found in Appendix F. 
Table 6. Summary Table of PDII and Descriptive Rating for Dermal Irritation

\begin{tabular}{|c|c|c|c|}
\hline Test Substance & Exposure & PDII & Descriptive Rating \\
\hline \multirow{2}{*}{ JP-8 } & Occluded & 2.5 & Moderately Irritating \\
\cline { 2 - 4 } & Semi-occluded & 1.1 & Slightly Irritating \\
\hline \multirow{2}{*}{$\begin{array}{c}\text { Gevo ATJ SPK } \\
\text { (non-bio) }\end{array}$} & Occluded & 1.6 & Slightly Irritating \\
\cline { 2 - 4 } & Semi-occluded & 1.0 & Slightly Irritating \\
\hline $\begin{array}{c}\text { Gevo ATJ SPK } \\
\text { (bio) }\end{array}$ & Occluded & 2.4 & Moderately Irritating \\
\cline { 2 - 4 } & Semi-occluded & 1.0 & Slightly Irritating \\
\hline \multirow{2}{*}{ SB ATJ SPK (original) } & Occluded & 2.3 & Moderately Irritating \\
\cline { 2 - 4 } & Semi-occluded & 1.2 & Slightly Irritating \\
\hline \multirow{2}{*}{ SB ATJ SPK (current) } & Occluded & 2.2 & Moderately Irritating \\
\cline { 2 - 4 } & Semi-occluded & 1.3 & Slightly Irritating \\
\hline
\end{tabular}

\subsection{Compliance, Quality Assurance and Data Retention}

The required compliance and quality assurance statements for Good Laboratory Practices (GLP) can be found in Appendix G. The U.S. Air Force, through the Henry M. Jackson Foundation for the Advancement of Military Medicine, has title to all documentation records, raw data, specimens, or other work product generated during the performance of the study. All remaining work products generated by WIL Research, including raw paper data and specimens, are retained in the WIL Research Archives as specified in the study protocol. Reserve samples of the test substances, pertinent electronic storage media, and the original final report are retained in the WIL Research Archives in compliance with regulatory requirements.

\subsection{DISCUSSION AND CONCLUSIONS}

There were no deaths or remarkable body weight changes noted during this dermal irritation study in male New Zealand white rabbits. Dermal findings during the study ranged from very slight to moderate erythema and very slight to moderate edema. A score of moderately irritating, as evaluated by the PDII and descriptive rating, was determined for all occluded exposures to these jet fuels except for the Gevo ATJ SPK (non-bio), which resulted in a slightly irritating score when occluded. All semi-occluded exposures to all test substances were slightly irritating. The finding of very slight to slight erythema and/or edema that persisted through study day 14 for the occluded and very slight to slight erythema that persisted through study day 14 for the semi-occluded exposures to all fuels evaluated was unprecedented (see discussion below). Only edema resolved back to normal by day 14 for the semi-occluded exposures to all of the fuels in this study. 
Petroleum-derived JP-8 (POSF 4658+) has been tested previously in this assay (Hurley et al., 2011; Mattie et al., 2013; Sterner et al., 2014a, 2014b). In the current study, JP-8 (POSF 4658+) was found to be slightly and moderately irritating under semi-occluded and occluded conditions, respectively. Hurley et al. (2011) calculated the same ratings; however, edema had resolved by 24 hours and erythema resolved between 4 and 7 days. Mattie et al. (2013) and Sterner et al. (2014a) found the same fuel to be only slightly irritating, regardless of occlusion type; erythema but not edema persisted through study day 14 in both occlusion groups. Sterner et al. (2014b) also found this fuel to be slightly irritating in both exposures. No edema was present for this fuel at any time point; erythema cleared between day 4 and 7. It is unclear why both erythema and edema should persist so long in this iteration.

SB ATJ SPK (old) was previously found to be slightly irritating, in both occluded and semioccluded conditions (Sterner et al., 2014a). Some differences in results are expected with jet fuels, given the variation discussed above with petroleum-derived JP-8 (POSF 4658+). Again, persistent edema is unprecedented with any of these fuels.

Gevo ATJ SPK (non-bio) was the only fuel tested herein with a different outcome from petroleum-derived JP-8. This alternative fuel was determined to be only slightly irritating during a fully occluded exposure. Since both Gevo fuels are refined from supposedly single chemical (isobutanol) feedstocks of different sources (petrochemical and biological), differences in dermal irritation potential were not anticipated. Table 2, the GC x GC summary, shows few composition differences between the two Gevo fuels; the petrochemically-derived fuel contains a slightly lower isoparaffin mass percentage as compared to the biologically-derived fuel. Upon examination of the more complete GC x GC results in Appendix A, a number of small differences were observed in composition. Gevo ATJ SPK (non-bio) has the lowest mass percentage of C10 and C11 isoparaffins among the fuels tested in this study, including Gevo ATJ SPK (bio). In addition, the C13/14 and C16 mass percentages were lower in the Gevo ATJ SPK (non-bio) than the Gevo ATJ SPK (bio). While these differences are documented, they are so small proportionally compared to the complexity of the fuels' compositions that they were not considered causal. Further investigation into the dermal irritation potential of a number of isoparaffins alone could be warranted.

In general, the SPK fuels tested in this study appeared to be equally irritating as petroleumderived JP-8. Only Gevo ATJ SPK (old) was found to be less (slightly) irritating in the occluded exposure. In conclusion, the four ATJ SPK alternative fuels tested in a dermal irritation assay in New Zealand white rabbits were found to be equivalent to or less irritating than petroleumderived JP-8. Based on this assay, normal handling of these fuels would not be expected to result in increased dermal irritation among Airmen. 


\subsection{REFERENCES}

AVMA. 2007. AVMA Guidelines on Euthanasia (Formerly Report of the AVMA Panel on Euthanasia). Schaumburg IL: American Veterinary Medical Association. June 2007.

Blakeley, K. 2012. DOD Alternative Fuels: Policy, Initiatives and Legislative Activity. Washington, D.C.: Congressional Research Service.

Draize, J.H. 1965. Appraisal of the Safety of Chemicals in Foods, Drugs and Cosmetics Dermal Toxicity. Association of Food and Drug Officials of the United States, Topeka, KS. pp. 49-52.

Gevo. 2014. Our Science and Technology. http://www.gevo.com/about/our-business/ourscience-and-technology/. Accessed 16 September 2014.

Hurley, J.M., Wagner, D., Sterner, T.R. and Mattie, D.R. 2011. Acute dermal irritation study of JP-8 and S-8 in New Zealand white rabbits. Wright-Patterson AFB, OH: Air Force Research Laboratory, Applied Biotechnology Branch. AFRL-RH-WP-TR-2011-0054, ADA546698.

Mattie, D.R., Hurley, J.M., Riccio, E.S. and Sterner, T.R. 2013. Acute Dermal Irritation Study and Salmonella-Escherichia coli/Microsome Plate Incorporation Assay of Hydroprocessed Esters and Fatty Acids (HEFA) Bio-Based Jet Fuels. Wright-Patterson AFB OH: Air Force Research Laboratory, Molecular Bioeffects Branch. AFRL-RH-WP-TR-2012-0011, ADA584649.

NRC. 2011. Guide for the Care and Use of Laboratory Animals. Eighth Edition. National Academy Press, Washington, D.C. Institute of Laboratory Animal Resources, Commission on Life Sciences, National Research Council.

OECD. 2002. OECD Guideline for the Testing of Chemicals. Guideline 404 Acute Dermal Irritation/Corrosion. Organisation for Economic Co-operation and Development, Paris.

Sterner, T.R., Hurley, J.M. and Mattie, D.R. 2014a. Acute Dermal Irritation Study of Ten Jet Fuels in New Zealand White Rabbits: Comparison of Synthetic and Bio-Based Jet Fuels with Petroleum JP-8. Wright-Patterson AFB OH: Air Force Research Laboratory, Human Effectiveness Directorate, Bioeffects Division, Molecular Bioeffects Branch. AFRL-RH-WPTR-2014-0045, ADA606124.

Sterner, T.R., Hurley, J.M., Edwards, J.T., Shafer, L.M. and Mattie, D.R. 2014b. Acute Dermal Irritation Study of Six Jet Fuels in New Zealand White Rabbits: Comparison of Four BioBased Jet Fuels with Two Petroleum JP-8 Fuels. Wright-Patterson AFB OH: Air Force Research Laboratory, Human Effectiveness Directorate, Bioeffects Division, Molecular Bioeffects Branch. AFRL-RH-WP-TR-2014-0046, ADA606443.

Striebich, R.C., Shafer, L.M., Adams, R.K., West, Z.J., DeWitt, M.J., Zabarnick, S. 2014. Hydrocarbon Group-Type Analysis of Petroleum-Derived and Synthetic Fuels using TwoDimensional Gas Chromatography. Energy \& Fuels 28: 5696-5706.

Swedish Biofuels. 2014a. Projects. http://www.swedishbiofuels.se/projects. Accessed 16 September 2014.

Swedish Biofuels. 2014b. Process. http://www.swedishbiofuels.se/process. Accessed 16 September 2014.

U.S. EPA. 1998. Health Effects Test Guidelines: OPPTS 870.2500 Acute Dermal Irritation. Washington, D.C.: U.S. Environmental Protection Agency, Office of Prevention, Pesticides and Toxic Substances. EPA 712-C-98-196. 


\section{APPENDIX A. COMPREHENSIVE TWO-DIMENSIONAL GAS CHROMATOGRAPHY ANALYSIS AND COMPARISON OF FUELS COMPONENTS}

\begin{tabular}{|c|c|c|c|c|c|}
\hline Fuel & $\begin{array}{c}\text { Baseline } \\
\text { JP-8 }\end{array}$ & $\begin{array}{c}\text { Gevo } \\
\text { ATJ SPK } \\
\text { (non-bio) }\end{array}$ & $\begin{array}{c}\text { Gevo } \\
\text { ATJ SPK } \\
\text { (bio) }\end{array}$ & $\begin{array}{c}\text { SB } \\
\text { ATJ SPK } \\
\text { (old) }\end{array}$ & $\begin{array}{c}\text { SB } \\
\text { ATJ SPK } \\
\text { (new) }\end{array}$ \\
\hline POSF & 4658 & 7695 & 9641 & 5668 & 7633 \\
\hline Component & Mass \% & Mass \% & Mass \% & Mass \% & Mass \% \\
\hline \multicolumn{6}{|c|}{ Aromatics } \\
\hline \multicolumn{6}{|l|}{ Alkylbenzenes } \\
\hline benzene (C06) & $<0.01$ & $<0.01$ & $<0.01$ & $<0.01$ & $<0.01$ \\
\hline toluene (C07) & 0.16 & $<0.01$ & $<0.01$ & $<0.01$ & $<0.01$ \\
\hline C2-benzene (C08) & 0.78 & $<0.01$ & $<0.01$ & $<0.01$ & 0.18 \\
\hline C3-benzene (C09) & 2.24 & $<0.01$ & $<0.01$ & 13.10 & 2.64 \\
\hline C4-benzene (C10) & 3.02 & 0.01 & $<0.01$ & 0.04 & 3.72 \\
\hline C5-benzene (C11) & 2.48 & $<0.01$ & $<0.01$ & $<0.01$ & 2.14 \\
\hline C6-benzene (C12) & 1.93 & $<0.01$ & $<0.01$ & 0.02 & 1.21 \\
\hline C7-benzene (C13) & 1.19 & $<0.01$ & $<0.01$ & $<0.01$ & 0.42 \\
\hline C8-benzene (C14) & 0.89 & $<0.01$ & $<0.01$ & $<0.01$ & 0.11 \\
\hline C9+-benzene (C15+) & 1.00 & 0.03 & $<0.01$ & $<0.01$ & 0.03 \\
\hline Total Alkylbenzenes & 13.69 & 0.24 & $<0.01$ & 13.16 & 10.47 \\
\hline \multicolumn{6}{|c|}{ Diaromatics (Naphthalenes, Biphenyl, etc.) } \\
\hline diaromatic-C10 & 0.12 & $<0.01$ & $<0.01$ & $<0.01$ & $<0.01$ \\
\hline diaromatic-C11 & 0.42 & $<0.01$ & $<0.01$ & $<0.01$ & $<0.01$ \\
\hline diaromatic-C12 & 0.60 & $<0.01$ & $<0.01$ & $<0.01$ & $<0.01$ \\
\hline diaromatic-C13 & 0.40 & $<0.01$ & $<0.01$ & $<0.01$ & $<0.01$ \\
\hline diaromatic-C14+ & 0.23 & $<0.01$ & $<0.01$ & $<0.01$ & $<0.01$ \\
\hline Total Alkylnaphthalenes & 1.76 & $<0.01$ & $<0.01$ & $<0.01$ & $<0.01$ \\
\hline \multicolumn{6}{|c|}{ Cycloaromatics (Indans, Tetralins, etc.) } \\
\hline cycloaromatic-C09 & 0.04 & $<0.01$ & $<0.01$ & $<0.01$ & 0.01 \\
\hline cycloaromatic-C10 & 0.43 & $<0.01$ & $<0.01$ & $<0.01$ & 0.15 \\
\hline cycloaromatic-C11 & 1.13 & $<0.01$ & $<0.01$ & $<0.01$ & 0.56 \\
\hline cycloaromatic-C12 & 1.63 & $<0.01$ & $<0.01$ & 0.01 & 0.60 \\
\hline cycloaromatic-C13 & 1.45 & $<0.01$ & $<0.01$ & $<0.01$ & 0.27 \\
\hline cycloaromatic-C14 & 0.71 & $<0.01$ & $<0.01$ & $<0.01$ & 0.09 \\
\hline cycloaromatics-C15+ & 0.41 & $<0.01$ & $<0.01$ & $<0.01$ & 0.02 \\
\hline Total Cycloaromatics & 5.79 & 0.01 & $<0.01$ & 0.02 & 1.71 \\
\hline Total Aromatics & 21.24 & 0.25 & 0.01 & 13.18 & 12.18 \\
\hline \multicolumn{6}{|c|}{ Paraffins } \\
\hline \multicolumn{6}{|l|}{ iso-Paraffins } \\
\hline C07 and lower-iso & 0.23 & 0.31 & 0.07 & 0.02 & 0.12 \\
\hline C08-isoparaffins & 0.56 & 0.86 & 1.06 & $<0.01$ & 0.14 \\
\hline C09-isoparaffins & 1.08 & 0.18 & 0.26 & $<0.01$ & 1.85 \\
\hline C10-isoparaffins & 3.59 & 0.13 & 0.23 & 2.87 & 7.32 \\
\hline C11-isoparaffins & 5.12 & 0.26 & 0.66 & 17.83 & 7.24 \\
\hline C12-isoparaffins & 5.31 & 82.01 & 76.07 & 57.41 & 8.29 \\
\hline C13-isoparaffins & 5.25 & \multirow{2}{*}{1.71} & \multirow{2}{*}{3.11} & 6.12 & 9.35 \\
\hline C14-isoparaffins & 4.44 & & & 2.04 & 6.52 \\
\hline C15-isoparaffins & 3.10 & $<0.01$ & $<0.01$ & $<0.01$ & 2.44 \\
\hline
\end{tabular}




\begin{tabular}{|c|c|c|c|c|c|}
\hline C16-isoparaffins & 1.66 & 10.14 & 16.85 & $<0.01$ & 0.68 \\
\hline C17-isoparaffins & 0.69 & $<0.01$ & $<0.01$ & $<0.01$ & 0.15 \\
\hline C18-isoparaffins & 0.19 & $<0.01$ & $<0.01$ & $<0.01$ & 0.03 \\
\hline C19-isoparaffins & 0.08 & $<0.01$ & $<0.01$ & $<0.01$ & $<0.01$ \\
\hline C20-isoparaffins & 0.02 & 2.67 & 1.12 & $<0.01$ & $<0.01$ \\
\hline Total iso-Paraffins & 31.34 & 98.27 & 99.43 & 86.30 & 44.14 \\
\hline \multicolumn{6}{|l|}{ n-Paraffins } \\
\hline n-C07 and lower & 0.15 & $<0.01$ & $<0.01$ & 0.00 & 0.02 \\
\hline n-C08 & 0.54 & $<0.01$ & $<0.01$ & $<0.01$ & 0.03 \\
\hline n-C09 & 1.14 & $<0.01$ & 0.02 & $<0.01$ & 0.11 \\
\hline $\mathrm{n}-\mathrm{C} 10$ & 2.55 & $<0.01$ & $<0.01$ & $<0.01$ & 0.23 \\
\hline $\mathrm{n}-\mathrm{C} 11$ & 3.62 & $<0.01$ & $<0.01$ & 0.04 & 0.12 \\
\hline $\mathrm{n}-\mathrm{C} 12$ & 3.70 & $<0.01$ & $<0.01$ & 0.01 & 0.08 \\
\hline $\mathrm{n}-\mathrm{C} 13$ & 2.86 & 0.02 & $<0.01$ & $<0.01$ & 0.06 \\
\hline $\mathrm{n}-\mathrm{C} 14$ & 2.17 & $<0.01$ & $<0.01$ & $<0.01$ & 0.02 \\
\hline $\mathrm{n}-\mathrm{C} 15$ & 1.28 & $<0.01$ & $<0.01$ & $<0.01$ & $<0.01$ \\
\hline $\mathrm{n}-\mathrm{C} 16$ & 0.61 & $<0.01$ & $<0.01$ & $<0.01$ & $<0.01$ \\
\hline n-C17 & 0.27 & $<0.01$ & $<0.01$ & $<0.01$ & $<0.01$ \\
\hline $\mathrm{n}-\mathrm{C} 18$ & 0.05 & $<0.01$ & $<0.01$ & $<0.01$ & $<0.01$ \\
\hline $\mathrm{n}-\mathrm{C} 19$ & 0.02 & $<0.01$ & $<0.01$ & $<0.01$ & $<0.01$ \\
\hline $\mathrm{n}-\mathrm{C} 20$ & $<0.01$ & $<0.01$ & $<0.01$ & $<0.01$ & $<0.01$ \\
\hline $\mathrm{n}-\mathrm{C} 21$ & $<0.01$ & $<0.01$ & $<0.01$ & $<0.01$ & $<0.01$ \\
\hline n-C22 & $<0.01$ & $<0.01$ & $<0.01$ & $<0.01$ & $<0.01$ \\
\hline $\mathrm{n}-\mathrm{C} 23$ & $<0.01$ & $<0.01$ & 0.02 & $<0.01$ & $<0.01$ \\
\hline Total n-Paraffins & 19.00 & 0.02 & 0.02 & 0.05 & 0.66 \\
\hline \multicolumn{6}{|c|}{ Cycloparaffins } \\
\hline \multicolumn{6}{|l|}{ Monocycloparaffins } \\
\hline C07 and lower-monocycloparaffins & 0.20 & $<0.01$ & 0.04 & 0.02 & $<0.01$ \\
\hline C08-monocycloparaffins & 0.69 & $<0.01$ & 0.12 & $<0.01$ & 0.69 \\
\hline C09-monocycloparaffins & 1.67 & 0.02 & $<0.01$ & $<0.01$ & 6.57 \\
\hline C10-monocycloparaffins & 3.26 & 0.01 & $<0.01$ & $<0.01$ & 9.41 \\
\hline C11-monocycloparaffins & 4.11 & 0.71 & 0.25 & 0.11 & 8.89 \\
\hline C12-monocycloparaffins & 4.07 & 0.05 & 0.02 & 0.13 & 6.19 \\
\hline C13-monocycloparaffins & 3.65 & 0.02 & 0.03 & $<0.01$ & 4.47 \\
\hline C14-monocycloparaffins & 2.43 & $<0.01$ & $<0.01$ & 0.14 & 2.17 \\
\hline C15-monocycloparaffins & 1.55 & $<0.01$ & $<0.01$ & $<0.01$ & 0.59 \\
\hline C16-monocycloparaffins & 0.64 & $<0.01$ & $<0.01$ & $<0.01$ & 0.08 \\
\hline C17-monocycloparaffins & 0.28 & 0.03 & 0.03 & $<0.01$ & 0.02 \\
\hline C18-monocycloparaffins & 0.06 & 0.07 & $<0.01$ & $<0.01$ & $<0.01$ \\
\hline C19+-monocycloparaffins & 0.03 & 0.06 & 0.02 & $<0.01$ & $<0.01$ \\
\hline Total Monocycloparaffins & 22.64 & 0.97 & 0.52 & 0.41 & 39.09 \\
\hline \multicolumn{6}{|c|}{ Dicycloparaffins (Decalins, Bihexyls, etc.) } \\
\hline C08-dicycloparaffins & 0.02 & $<0.01$ & $<0.01$ & $<0.01$ & $<0.01$ \\
\hline C09-dicycloparaffins & 0.29 & $<0.01$ & $<0.01$ & $<0.01$ & 0.09 \\
\hline C10-dicycloparaffins & 0.43 & $<0.01$ & $<0.01$ & 0.03 & 0.63 \\
\hline C11-dicycloparaffins & 1.26 & $<0.01$ & $<0.01$ & $<0.01$ & 0.97 \\
\hline C12-dicycloparaffins & 1.22 & 0.01 & $<0.01$ & $<0.01$ & 1.26 \\
\hline C13-dicycloparaffins & 1.42 & $<0.01$ & $<0.01$ & $<0.01$ & 0.71 \\
\hline C14-dicycloparaffins & 0.82 & $<0.01$ & $<0.01$ & 0.01 & 0.16 \\
\hline C15-dicycloparaffins & 0.21 & 0.06 & $<0.01$ & $<0.01$ & 0.03 \\
\hline
\end{tabular}




\begin{tabular}{|c|c|c|c|c|c|}
\hline C16-dicycloparaffins & 0.02 & 0.08 & $<0.01$ & $<0.01$ & $<0.01$ \\
\hline C17+-dicycloparaffins & 0.03 & 0.31 & $<0.01$ & $<0.01$ & $<0.01$ \\
\hline Total Dicycloparaffins & 5.73 & 0.50 & 0.02 & 0.05 & 3.85 \\
\hline \multicolumn{6}{|l|}{ Tricycloparaffins } \\
\hline C10-tricycloparaffins & $<0.01$ & $<0.01$ & $<0.01$ & $<0.01$ & $<0.01$ \\
\hline C11-tricycloparaffins & 0.05 & $<0.01$ & $<0.01$ & $<0.01$ & $<0.01$ \\
\hline C12-tricycloparaffins & $<0.01$ & $<0.01$ & $<0.01$ & $<0.01$ & 0.06 \\
\hline Total Tricycloparaffins & 0.05 & $<0.01$ & $<0.01$ & $<0.01$ & 0.06 \\
\hline Total Cycloparaffins & 28.42 & 1.47 & 0.54 & 0.47 & 43.00 \\
\hline TOTAL & 100.00 & 100.01 & 100.00 & 100.00 & 99.98 \\
\hline
\end{tabular}




\section{APPENDIX B. STUDY PROTOCOL}

\section{Deviation from the Protocol}

This study was conducted in accordance with the protocol, except for the following:

- Protocol Section 5.8 states that each animal will be uniquely identified by a plastic eartag displaying the animal number. However, the animals were identified using BMDS microchips.

Reason for Deviation: Available WIL Research stock animals had been previously identified by microchips.

This deviation did not negatively impact the quality or integrity of the data, or the outcome of the study. 


\title{
)) WIL
}

\author{
Study Number: WIL-773003 \\ PROTOCOL AMENDMENT 1 \\ Sponsor: The Henry M. Jackson Foundation \\ for the Advancement of Military Medicine
}

Title of Study:

Acute Dermal Irritation Study of Four Bio-Based Jet Fuels in New Zealand White Rabbits

Protocol Modifications:

\section{1) 3 STUDY SCHEDULE:}

The section is replaced with the following:

Proposed Experimental Start Date: $\quad$ February 26, 2013

Proposed Experimental Termination Date: $\quad$ March 12, 2013

Proposed Audited Draft Report Date: $\quad$ April 23, 2013

\section{2) 4.5 Test Substance \#5 Identification / Lot Number:}

The section is replaced with the following:

Swedish Biofuel (Current) / Lot no. POSF 7633 (With additives, now Lot no. 8452)

Reason for Protocol Modification:

1) Change in study schedule.

2) Clarification of lot number for test substance \#5. 


\section{Approval:}

Sponsor's approval was obtained via e-mail on 15 February 2013.

The Henry M. Jackson Foundation for the Advancement of Military Medicine

$$
\frac{R_{\substack{\text { David R. Mattie, PhD, DABT } \\ \text { Sponsor Representative }}}^{15 \mathrm{Fef} / 3}}{\text { Date }}
$$

WIL Research

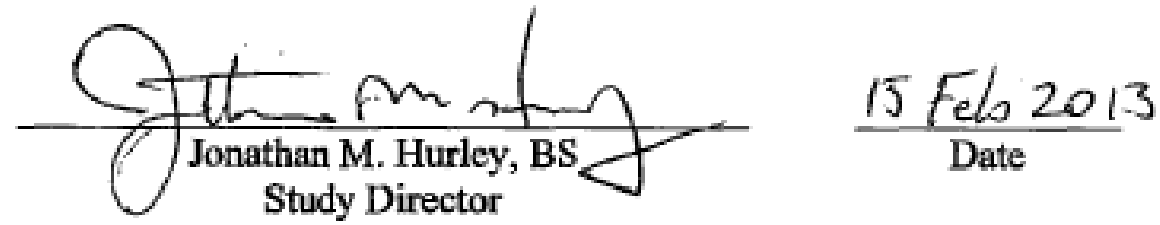




\section{))( WIL RESEARCH}

Page 1 of 14

WIL-T73003

08 February 2013

\section{PROTOCOL}

Acute Dermal Irritation Study of

Four Bio-Based Jet Fuels in New Zealand White Rabbits

Submitted To:

The Henry M. Jackson Foundation

for the Advancement of Military Medicine

1401 Rockville Pike, Suite 600

Rockville, MD 20852

WIL Research

1407 George Road

Ashland, OH 44805-8946 


\section{OBJECTIVE:}

To determine the irritative potential of the test substances following a single exposure to the skin of albino rabbits.

This protocol has been designed and the study will be conducted in general compliance with the following guidelines:

U.S. Environmental Protection Agency (U.S. EPA) Office of Prevention, Pesticides and Toxic Substance (OPPTS) guideline 870.2500 (1998).

Organisation for Economic Cooperation and Development (OECD) Guidelines for Testing of Chemicals, Section 404 (2002).

The European Union (EU) Guideline in the Official Journal of the European Communities [92/69, Annex V, B4 (1992)].

The study will be conducted in compliance with the U.S. EPA Good Laboratory Practices (40 CFR Part 792); with the exception that analytical confirmation of the concentration, homogeneity and stability of the dosing mixture (if prepared) will not be performed.

\section{PERSONNEL INVOLVED IN THE STUDY:}

\subsection{Sponsor Representative:}

David R. Mattie, PhD, DABT

Molecular Bioeffects Branch

$711 \mathrm{HP}$ W/RHDJ

2729 R Street, Bldg 837

Wright-Patterson AFB, OH 45433-5707

Phone: (937) 904-9569

E-mail: David.Mattie@wpafb.af.mil

\subsection{WIL Research Study Director:}

Jonathan M. Hurley, BS

Staff Toxicologist and Head of Acute Toxicology

Phone: (419) 289-8700

Fax: (419) 289-3650

E-mail: jon.hurley@wilresearch.com 


\subsection{WIL Research Departmental Responsibilities:}

Teresa D. Morris, BS

Assistant Director, General Toxicology

Emergency Contact

Tel: (419) 282-6930

E-mail: teresa.morris@wilresearch.com

Steven D. Barkyoumb, DVM, PhD, DACVP

Senior Vice-President, Global Operations - Safety Assessment

Alex K. Eapen, PhD, DABT

Associate Director, General Toxicology

Howard E. Moody, MS

Vice President, Chief Information Officer

Bennett J. Varsho, MPH, DABT

Director, Non-Clinical Safety Operations

Sally A. Keets, AS

Senior Operations Manager, Vivarium

Erica L. Lashley, BS, LAT

Operations Manager, Toxicology

Theresa M. Rafeld

Group Manager, Formulations Laboratory

Carol A. Kopp, BS, LAT

Manager, Gross Pathology and

Developmental Toxicology Laboratory

Gwendalyn M. Maginnis, DVM

Attending Veterinarian

Robert A. Wally, BS

Operations Manager, Reporting

\& Technical Support Services

Heather L. Johnson, BS, RQAP-GLP

Manager, Quality Assurance 


\section{STUDY SCHEDULE:}

Proposed Experimental Start Date: February 19,201 3

Proposed Experimental Termination Date: March 5, 2013

Proposed Audited Draft Report Date: April 16, 2013

\section{TEST SUBSTANCES:}

The Sponsor assumes responsibility for purity and stability determinations (including under test conditions). Information on composition and method of synthesis will be held by the Sponsor. Test Substance \#1 is the operational fuel with which the alternative fuels will be compared. Test Substances \#2-5 are alternative fuels for dermal testing.

\subsection{Test Substance \#1 Identification / Lot Number:}

JP-8 (Baseline fuel) / Lot no. POSF 4658

\subsection{Test Substance \#2 Identification / Lot Number:}

Gevo, non-bio-derived / Lot no. POSF 7695

\subsection{Test Substance \#3 Identification / Lot Number:}

Gevo, bio-derived / Lot no. POSF 9641

\subsection{Test Substance \#4 Identification / Lot Number:}

Swedish Biofuel (Original) / Lot no. POSF 5668

\subsection{Test Substance \#5 Identification / Lot Number:}

Swedish Biofuel (Current) / Lot no. POSF 7633

\subsection{Purity:}

Responsibility of the Sponsor

\subsection{Stability:}

Considered to be stable for years when properly stored 


\subsection{Physical Descriptions:}

To be documented by WIL Research

\subsection{Storage Conditions:}

Store at room temperature. Keep containers closed tightly. Use and store these materials in cool, dry, well-ventilated areas away from heat, direct sunlight, hot metal surfaces and all sources of ignition.

\subsection{Personnel Safety:}

At minimum, appropriate gloves, eye protection and long sleeves (lab coat) are to be worn during dose administration. Refer to Material Safety Data Sheets for complete available information.

\subsection{Retention Samples:}

Retention samples of the test substances (as received) will be collected in accordance with WIL Research SOP No. T2-001.

\subsection{Unused Test Substances:}

Unused portions of the test substances will be returned following the issuance of the final study report to the contact below.

David R. Mattie, PhD, DABT

711 HPW/RHDJ

2729 R Street, Bldg 837

Wright-Patterson AFB, OH 45433-5707

Phone: (937) 904-9569

Email: David.Mattie@WPAFB.AF.MIL

\section{TEST SYSTEM:}

\subsection{Species:}

Albino rabbit (Oryctolagus cuniculus)

\subsection{Breed:}

New Zealand White 


\subsection{Source:}

Covance Research Products, Inc. (USDA License \# 23-A-0180)

(Documentation of the specific breeding facility will be maintained in the study records and included in the final report.)

\subsection{Number on Study:}

Six animals from the acute stock colony

\subsection{Sex:}

Males and/or females (females will be nulliparous and nonpregnant)

\subsection{Body Weight Range:}

$2.0 \mathrm{~kg}$ or greater

\subsection{Approximate Age:}

Young adult, at least 12 weeks old at initiation of dosing

\subsection{Identification System:}

Each animal will be uniquely identified by a plastic eartag displaying the animal number. Individual cage cards will be affixed to each cage and will display the animal number, group and study number.

\subsection{Justification for Selection:}

This species and breed is generally recognized as appropriate for acute dermal irritation studies. The number of animals selected is the minimum required to satisfy regulatory guidelines. The experimental design uses the procedures and standards required by the current federal and international regulations.

\section{SPECIFIC MAINTENANCE SCHEDULE:}

\subsection{Animal Housing:}

The animals will be housed individually in stainless steel cages in an environmentally controlled room. Animals will be housed in clean cages elevated above ground corncob bedding or other suitable material that will be changed at least twice each week. Animals will be changed out into clean cages approximately every two weeks. The facilities at WIL Research are fully accredited by the Association for Assessment and Accreditation of Laboratory Animal Care International (AAALAC International). 


\subsection{Environmental Conditions:}

Controls will be set to maintain the temperature at $66 \pm 5^{\circ} \mathrm{F}\left(19 \pm 3^{\circ} \mathrm{C}\right)$ and the relative humidity at $50 \pm 20 \%$. Temperature and relative humidity will be monitored continuously. Data for these two parameters will be scheduled for automatic collection on an hourly basis. Fluorescent lighting controlled by light timers will provide illumination for a 12-hour light/dark photoperiod.

Temporary adjustments to the light/dark cycles may be made to accommodate protocol specified activities. The ventilation rate will be set at a minimum of 10 room air changes per hour, $100 \%$ fresh air.

\subsection{Drinking Water:}

Municipal water will be available ad libitum. Filters servicing the automatic watering system will be changed regularly according to Standard Operating Procedures (SOPS). Municipal water supplying the laboratory is analyzed for contaminants according to SOPS to ascertain that none are present at concentrations that would be expected to affect the outcome of the study and the results are maintained on file.

\subsection{Basal Diet:}

PMI Nutrition International, LLC Certified High Fiber Rabbit ab ie5t3@25 will be offered at approximately $150 \mathrm{~g} /$ day during the study. The amount of feed provided will be estimated and will not be documented. Standard Operating Procedures provide specifications for acceptable levels of heavy metals and pesticides that are reasonably expected to be present in the diet without interfering with the purpose or conduct of the study. Analyses are performed and provided by the manufacturer and the results are maintained on file.

\section{EXPERIMENTAL DESIGN:}

\subsection{Animal Receipt and Acclimation:}

Each animal was/will be inspected by a qualified technician upon receipt into the acute stock colony. Animals judged to be in good health and suitable as test animals were/will be acclimated to laboratory conditions for a minimum of five days. All animals were/will be weighed initially and permanently identified. During the acclimation period, each animal will be observed twice daily for changes in general appearance and behavior.

All relevant records and data collected during the acclimation period for animals used on this study will be maintained on file. 


\subsection{Veterinary Care:}

Animals will be monitored by the technical staff for any condition requiring possible veterinary care. If any such condition is identified, a staff veterinarian will be notified for an examination and evaluation. Animals will be treated as outlined in the Animal Welfare Act Compliance section of the protocol.

\subsection{Route and Rationale of Test Substance Administration:}

The route of administration will be dermal (clipped, intact skin) in order to evaluate the dermal irritation potential of the test substances. This study is intended to provide information on the health hazards likely to arise from a short-term exposure to the test substances by the dermal route.

\subsection{Organization of Treatment Groups:}

Following the acclimation period, animals will be arbitrarily selected from available stock based upon health and body weight and assigned to 2 groups of 3 rabbits/group as shown below. No separate control group will be utilized; each animal will serve as its own control. The skin of all test sites will be left intact (unabraded) .

\begin{tabular}{|c|c|c|c|c|}
\hline $\begin{array}{c}\text { Group } \\
\text { Number }\end{array}$ & Test Substances* & $\begin{array}{c}\text { Dose Volume } \\
\text { (mL/Test Substance) }\end{array}$ & Exposure Method & $\begin{array}{c}\text { Number of } \\
\text { Animals }\end{array}$ \\
\hline 1 & $\# 1, \# 2, \# 3, \# 4, \# 5$ & 0.5 & Occluded & 3 \\
\hline 2 & $\# 1, \# 2, \# 3, \# 4, \# 5$ & 0.5 & Semi-occluded & 3 \\
\hline
\end{tabular}

*\#1 = JP-8 (Baseline fuel); \#2 = Gevo, non-bio-derived, \#3 =; Gevo, bio-derived, \#4 = Swedish Biofuel (Original), \#5= Swedish Biofuel (Current)

\subsection{Test Material Preparation:}

The test substances will be administered undiluted as received at a dosage of $0.5 \mathrm{~mL}$. The $\mathrm{pH}$ will be determined and recorded.

\subsection{Animal Preparation:}

On the day prior to dermal applications, the back and flanks of each animal will be clipped free of hair with a small animal clipper. The clipped area on each animal will constitute approximately $20-25 \%$ of the total body surface area (actual size of area will not be recorded). Animals with dermal abnormalities or injuries will be excluded. 


\subsection{Method of Administration:}

Five sites located lateral to the midline of the back will be selected on each rabbit. The location of the test sites (designated A-E based upon five available site locations on the back of the rabbit) will be rotated so that no test substance is applied to the same site within a group of rabbits. The test sites will be delineated with four dots made with indelible ink spaced approximately 2.5 centimeters apart arranged in a square. All animals will receive a single application of five test substances.

Each test site will be immediately covered with a two ply, $2.5-\mathrm{cm}$ square gauze patch. The patch will be secured in place with surgical porous tape. For animals in the occluded exposure groups the trunk of the animal will be wrapped with plastic wrap to occlude the test site. The trunk of animals in both the occluded and semi-occluded groups will then be wrapped with gauze bandaging that will be secured with several wrappings of non-irritating tape. Elizabethan collars will be applied to each animal during the exposure period to prevent ingestion of the test substances andlor wrappings.

After the four hours of exposure, the bandages will be removed and residual test substance cleansed fiom the application sites using clean, disposable paper towels moistened with deionized water (as thoroughly as possible without irritating the skin). The same towel will not be used on more than one site.

\section{OBSERVATIONS:}

\subsection{Viability and Clinical Observations:}

All animals will be observed for mortality/moribundity twice daily (morning and afternoon) for the duration of the study. Moribund animals will be removed fiom study and euthanized by intravenous injection of sodium pentobarbital. All animals will receive a detailed physical examination on the day of dosing.

\subsection{Dermal Observations:}

Approximately 30-60 minutes after test substance removal, each test site will be examined and the degree of erythema and edema recorded according to the Draize technique (Appendix A). The presence of any other dermal findings will also be recorded. Additional examinations will be performed at approximately 24, 48 and 72 hours after patch removal. If no irritation is present at the 72-hour observation, the study may be terminated.

If irritation is present at the end of 72 hours, additional observations will be performed on days 4, 7 and 14, or until irritation subsides. The study need not normally exceed 14 days after application unless specifically requested and 
authorized by the Sponsor. Individual animals will be terminated if no irritation is present at the 72-hour or any subsequent observation. At the request of the Sponsor, observations may be terminated prior to 14 days and/or resolution of irritation.

The areas of application will be clipped free of hair a minimum of one hour before scoring, as needed during the study, to facilitate accurate dermal observations.

\subsection{Body Weights:}

The body weight of each animal will be determined on study day 0 and at termination.

\subsection{Gross Pathology:}

All animals will be euthanized by intravenous injection of sodium pentobarbital. A gross necropsy examination on major organ systems of the thoracic and visceral cavities will be conducted on all animals found dead or euthanized in extremis. Animals euthanized following study termination will be discarded without further examination.

\section{CALCULATION OF THE PRIMARY DERMAL IRRITATION INDEX:}

The Primary Dermal Irritation Index will be calculated from the scores recorded at 30-60 minutes, 24, 48 and 72 hours (after patch removal). The mean scores for erythema and edema will be calculated separately to the nearest tenth and added together. Based on this value, the grading system in Appendix A will be used to arrive at a primary dermal irritation descriptive rating for each test substance for the occluded and unoccluded method of exposure.

\section{REPORT:}

The final report will include, but will not necessarily be limited to, the following: compliance statement, summary, objective, test substance identification and receipt information, methods, observations, mortality, body weights, individual and summarized dermal scores/findings, classification of the test substance based on dermal irritation properties, results and discussion, key personnel, a signed QA statement and protocol deviation(s), if any.

WIL Research will submit one electronic copy (PDF with an MS Word copy of the report text for editing and comments) of an audited draft report in a timely manner upon completion of data collection prior to issuance of the final report. It is expected that the Sponsor will review the draft report and provide comments to WIL Research within a two-month time frame following submission. Within one month following 
receipt of the Sponsor's comments, WIL Research shall provide a revised draft report that incorporates the Sponsor's reasonable revisions and suggestions. One revision will be permitted as part of the cost of the study; additional changes or revisions may be made, at extra cost. WIL Research will submit the final report within two weeks of receiving authorization from the Sponsor. If the Sponsor's comments and/or authorization to finalize the report have not been received at WIL Research within one year following submission of the draft report, WIL Research may elect to finalize the report following appropriate written notification to the Sponsor. An electronic copy (hyperlinked and bookmarked PDF) of the final report will be provided. Requests for paper copies of the final report may result in additional charges.

\section{RECORDS TO BE MAINTAINED:}

All original raw data records (as defined by the applicable GLPs and WIL Research SOPs) generated by WIL Research will be collected and maintained in the WIL Research Archives as described in the following section.

\section{WORK PRODUCT:}

Sponsor will have title to all documentation records, raw data, slides, specimens, or other work product generated during the performance of the study. All work product including raw paper data, pertinent electronic storage media and specimens will be retained at no charge for a period of six months following issuance of the final report in the WIL Research Archives. Thereafter, WIL Research will charge a monthly archiving fee for retention of all work product. All work product will be stored in compliance with regulatory requirements.

Any work product, including documents, specimens, and samples, that are required by this protocol, its amendments, or other written instructions of the Sponsor, to be shipped by WIL Research to another location will be appropriately packaged and labeled as defined by WIL Research's SOPs and delivered to a common carrier for shipment. WIL Research will not be responsible for shipment following delivery to the common carrier.

\section{QUALITY ASSURANCE:}

The study will be audited by the WIL Research Quality Assurance Department while in progress to assure compliance with applicable Good Laboratory Practices and adherence to the protocol and to WIL Research SOPs. The raw data and draft report will be audited by the WE Research Quality Assurance Department to assure that the final report accurately describes the conduct and the findings of the study. 


\section{PROTOCOL MODIFICATION:}

Modification of the protocol may be accomplished during the course of this investigation. However, no changes will be made in the study design without the verbal or written permission of the Sponsor. In the event that the Sponsor verbally requests or approves changes in the protocol, such changes will be made by appropriate documentation in the form of protocol amendments. All alterations of the protocol and reasons for the modification(s) will be signed by the Study Director and the Sponsor Representative.

\section{ANIMAL WELFARE ACT COMPLIANCE:}

This study will comply with all applicable sections of the Final Rules of the Animal Welfare Act regulations (9 CFR). The Sponsor should make particular note of the following:

- The Sponsor signature on this protocol documents for the Study Director the Sponsor's assurance that, for the study described in this protocol there are no acceptable non-animal alternatives and the study does not unnecessarily duplicate previous experiments.

- Whenever possible, procedures used in this study have been designed to avoid or minimize discomfort, distress or pain to animals. All methods are described in this study protocol or in written laboratory SOPS.

- Animals that experience severe or chronic pain or distress that cannot be relieved will be painlessly euthanized as deemed appropriate by the veterinary staff and Study Director. The Sponsor will be advised by the Study Director of all circumstances which could lead to this action in as timely a manner as possible.

- Methods of euthanasia used during this study are in conformance with the abovereferenced regulation

- The Sponsor/Study Director has considered alternatives to procedures that may cause more than momentary or slight pain or distress to the animals and has provided a written narrative description (AWA covered species) of the methods and sources used to determine that alternatives are not available. 


\section{PROTOCOL APPROVAL:}

Sponsor approval received by the Study Director via e-mail on 07 February 2013.

The Henry M. Jackson Foundation for the Advancement of Military Medicine

$\frac{\text { Daid R.M athe }}{\substack{\text { David R Mattie, PhD, DABT } \\ \text { Sponsor Representative }}} \frac{8 \text { Fel-2013 }}{\text { Date }}$

WLL Research

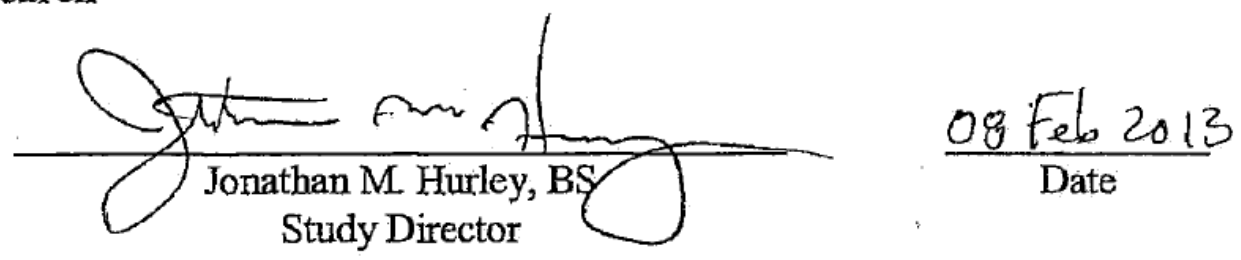




\title{
APPENDIX A
}

SCORING CRITERLA FOR DERMAL REACTIONS*

\section{$\underline{\text { Value }}$}

\author{
Erythema and Eschar Formation
}

$0 \quad$ No erythema

1 Very slight erythema (barely perceptible, edges of area not well defined)

$2 \quad$ Slight erythema (pale red in color and edges definable)

3 Moderate to severe erythema (definite red in color and area well defined)

4 Severe erythema (beet or crimson red) to slight eschar formation (injuries in depth)

$4 \quad$ Maximum possible erythema score

\section{Edema Formation}

$0 \quad$ No edema

1 Very slight edema (barely perceptible, edges of area not well defined)

2 Slight edema (edges of area well defined by definite raising)

3 Moderate edema (raised approximately $1 \mathrm{~mm}$ )

$4 \quad$ Severe edema (raised more than $1 \mathrm{~mm}$ and extending beyond area of exposure)

$4 \quad$ Maximum possible edema score

$8 \quad$ Maximum total possible Primary Irritation Score

DESCRIPTIVE RATINGS

Mean Primary Dermal Irritation Index

\begin{tabular}{cl} 
Range of Values & Descriptive Rating \\
\hline 0 & Nonirritating \\
$0.1-2.0$ & Slightly Irritating \\
$2.1-5.0$ & Moderately Irritating \\
$5.1-8.0$ & Severely Irritating
\end{tabular}

*Draize, J.H., 1965. The Appraisal of the Safety of Chemicals in Foods, Drugs and Cosmetics. Dermal Toxicity, pp. 46-59. Assoc. of Food and Drug Officials of the U.S., Topeka, Kansas and the EPA-OPPTS Health Effects Test Guidelines (1998). 


\section{APPENDIX C: SCORING CRITERIA FOR DERMAL REACTIONS}

\section{$\underline{\text { Evaluation of Dermal Reactions }^{\mathrm{a}}}$}

\section{Value Erythema and Eschar Formation}

\begin{tabular}{ll}
0 & No erythema \\
1 & Very slight erythema (barely perceptible, edges of area not well defined) \\
2 & Slight erythema (pale red in color and edges definable) \\
3 & Moderate to severe erythema (definite red in color and area well defined) \\
4 & Severe erythema (beet or crimson red) to slight eschar formation (injuries in depth) \\
\hline 4 & Maximum possible erythema score \\
Value & $\begin{array}{l}\text { Edema Formation } \\
0\end{array}$ \\
1 & No edema \\
2 & Very slight edema (barely perceptible, edges of area not well defined) \\
3 & Slight edema (edges of area well defined by definite raising) \\
4 & Moderate edema (raised approximately 1 mm)
\end{tabular}

\section{Descriptive Ratings}

\begin{tabular}{cl}
$\begin{array}{c}\text { Mean Primary Dermal Irritation Index } \\
\text { Range of Values }\end{array}$ & Descriptive Rating \\
\hline 0 & Nonirritating \\
$0.1-2.0$ & Slightly Irritating \\
$2.1-5.0$ & Moderately Irritating \\
$5.1-8.0$ & Severely Irritating
\end{tabular}

${ }^{\mathrm{a}}$ Draize, J.H., 1965. The Appraisal of the Safety of Chemicals in Foods, Drugs and Cosmetics. Dermal Toxicity, pp. 46-59. Assoc. of Food and Drug Officials of the U.S., Topeka, Kansas and the U.S. EPA OPPTS Health Effects Test Guidelines (1998). 


\section{APPENDIX D. DATA ACQUISITION AND REPORTING SYSTEMS}

\begin{tabular}{|c|c|}
\hline Program/System & Description \\
\hline $\begin{array}{l}\text { Archive Management } \\
\text { System (AMS) }\end{array}$ & $\begin{array}{l}\text { In-house developed application for storage, maintenance, and } \\
\text { retrieval of information for archived materials (e.g., lab } \\
\text { books, study data, wet tissues, slides, etc.). }\end{array}$ \\
\hline InSight ${ }^{(B)}$ Publisher & $\begin{array}{l}\text { Electronic publishing system (output is Adobe Acrobat, } \\
\text { PDF). }\end{array}$ \\
\hline Master Schedule & Maintains the master schedule for the company. \\
\hline $\begin{array}{l}\text { Metasys DDC Electronic } \\
\text { Environmental Control System }\end{array}$ & $\begin{array}{l}\text { Controls and monitors animal room environmental } \\
\text { conditions. }\end{array}$ \\
\hline Microsoft ${ }^{\circledR}$ Office 2007 & $\begin{array}{l}\text { Used in conjunction with the publishing software to generate } \\
\text { study reports. }\end{array}$ \\
\hline Provantis Dispense $^{\mathrm{TM}}$ & $\begin{array}{l}\text { Comprehensive system (Instem LSS Limited) to manage test } \\
\text { materials, including receipt, formulation instructions, and } \\
\text { accountability. }\end{array}$ \\
\hline $\begin{array}{l}\text { WIL Formulations Dispense } \\
\text { System (WFDS) }\end{array}$ & $\begin{array}{l}\text { In-house developed system for use in conjunction with } \\
\text { Provantis Dispense }{ }^{\mathrm{TM}} \text { to ensure proper storage and use of } \\
\text { formulations. }\end{array}$ \\
\hline WIL Metasys & $\begin{array}{l}\text { In-house developed system used to record and report animal } \\
\text { room environmental conditions. }\end{array}$ \\
\hline
\end{tabular}

Note: Version numbers of WTDMS ${ }^{\mathrm{TM}}$ (WIL Toxicology Data Management System) programs used for the study are presented on the report data tables (reporting programs); version numbers and release dates are otherwise maintained in the study records and/or facility records. 
ACUTE DERMAL STUDY OF FOUR BIO-BASED JET FUELS IN RABBITS

PAOJPCT NO. :WIL- 773003 TEMPERATURE/HOMIDITY - STUDY SUMMPY PEPOR

SPONSOR: 773 - H M JACKSON FOUNDATION

Page 1 of 4

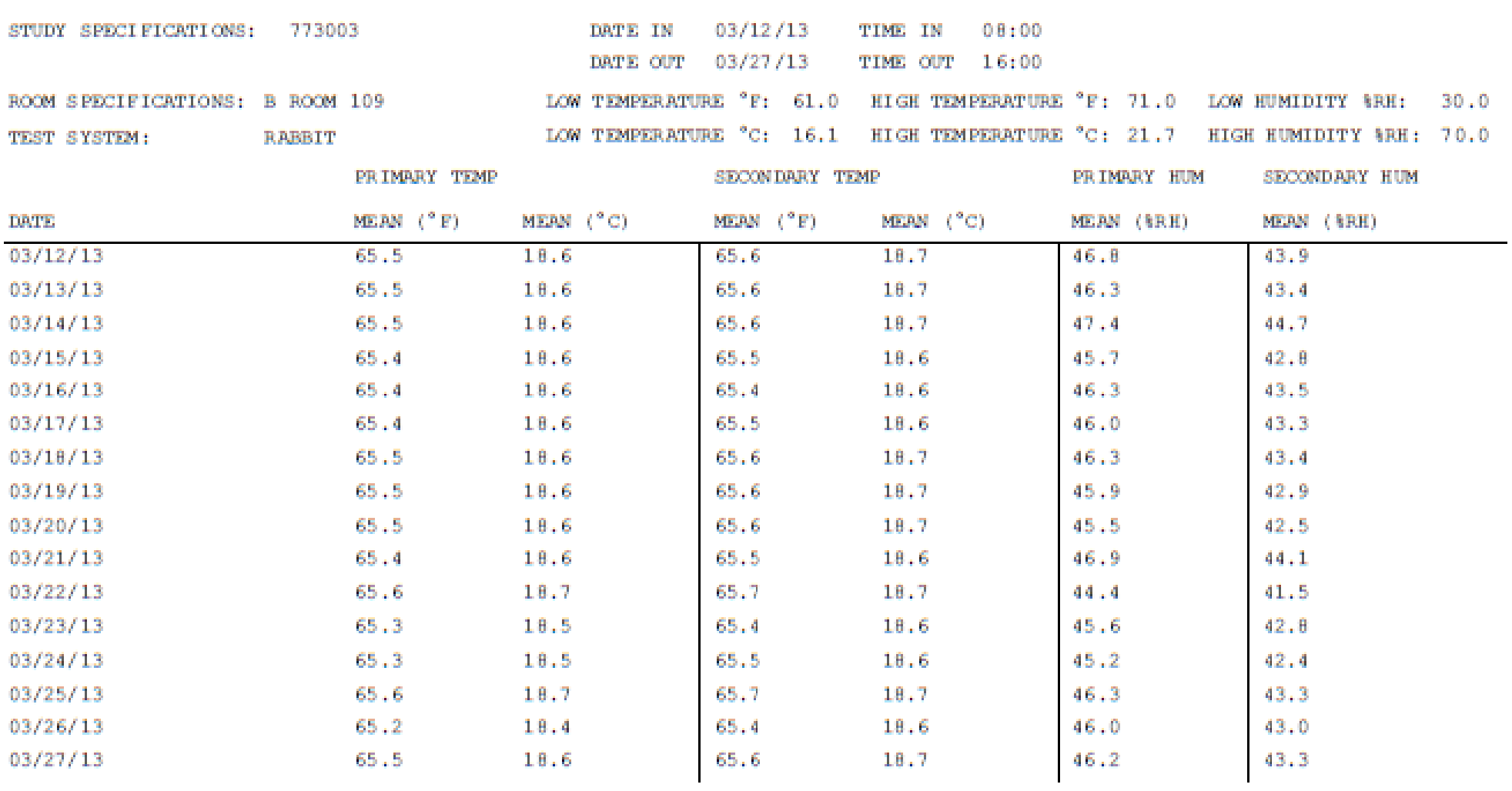


ACUTE DERMAL STUDY OF EOUR BIO-BASED JET FUELS IN RABBITS

PAOJDCT NO. :WIL- 773003

TEMPEPATURE/HIMIDITY - STUDY SUMMPY PEPORT

SPONSOR: 773 - H M JACKSON FOUNDATION

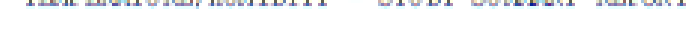

Page 2 of 4

\begin{tabular}{|c|c|c|c|c|c|c|c|}
\hline \multirow[b]{2}{*}{ DATE } & \multicolumn{3}{|c|}{ PR IMPRY TEMP } & \multicolumn{2}{|c|}{ SDCONDARY TEMP } & \multirow{2}{*}{$\begin{array}{l}\text { PRIMPRY HLM } \\
\text { MERN (IRH) }\end{array}$} & \multirow{2}{*}{$\begin{array}{l}\text { SDOONDARY HUM } \\
\text { MERN (IFH) }\end{array}$} \\
\hline & MEAN & $\left({ }^{\circ} \mathrm{F}\right)$ & MER ( $\left({ }^{\circ} \mathrm{C}\right)$ & MERS ( & MERs ("C) & & \\
\hline STMAORY OF DAILY MENSS & MEAN & $\operatorname{MrN}$ & $\operatorname{mox}$ & & & & \\
\hline PRIMARY TEMP 'F; & 65.4 & 65.2 & 65.6 & & & & \\
\hline PRIMPRY TEMP ${ }^{\circ} \mathrm{C}:$ & 18.6 & 18.4 & 18.7 & & & & \\
\hline SDCONDARY TEMP 'F: & 65.5 & 65.4 & 65.7 & & & & \\
\hline SDCONDARY TEMP ${ }^{\circ} \mathrm{C}$ : & 18.6 & 18.6 & 18.7 & & & & \\
\hline PRIMRFY HOM IFH: & 46.0 & 44.4 & 47,4 & & & & \\
\hline SDCONDAFY HUM IFH: & 43.1 & 41.5 & 44.7 & & & & \\
\hline N DAYS & 16 & & & & & & \\
\hline
\end{tabular}


PAOJPCT NO. :WIL- 773003

ACUTE DERMAL STUDY OF EOUR BIO-BASED JET FUELS IN RABBITS SPONSOR: 773 - H M JACKSON EOUNDATION

Page 3 of 4

\section{B FOCM 109 STMMNRY OF HOUHLY VNLUES}

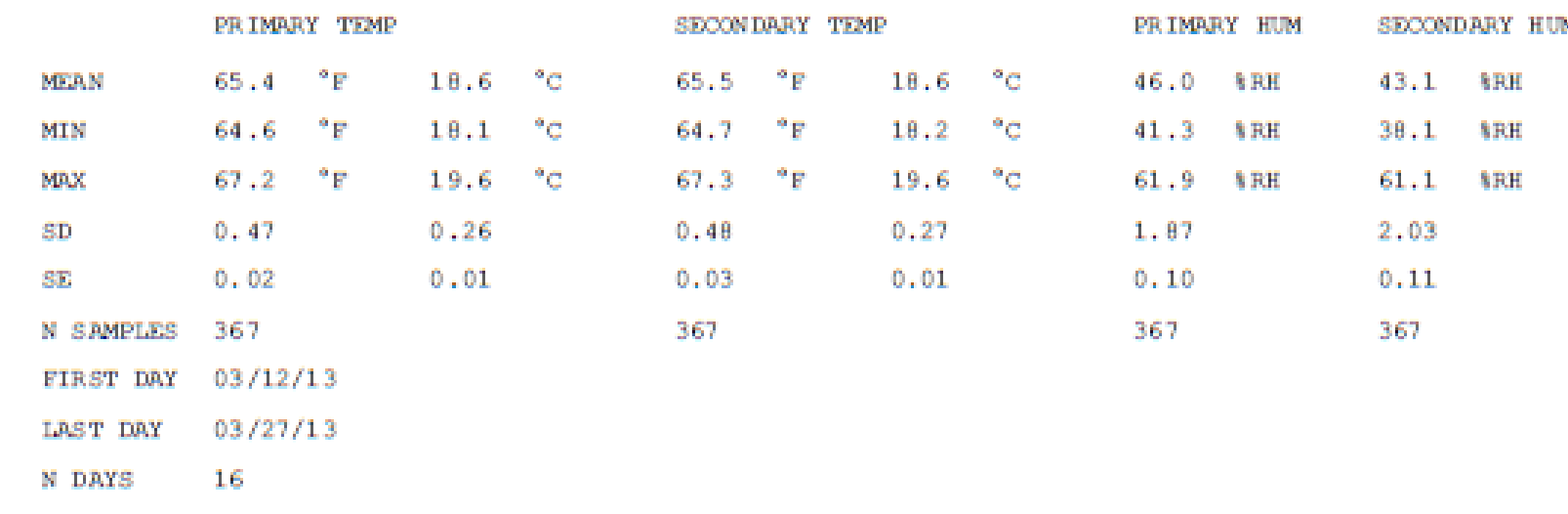

TEMPERATUPE/HUMIDITY - STUDY SUMMRY PEPORT 
ACUTE DERMAL STUDY OF EOUR BIO-BASED JET FUELS DN RABBITS

PROJPCT NO. :WIL- 773003 TEMP БRRTUAE/HTMIDITY - STUDY SUMMPRY REPORT

\section{STUDY 773003 SLMMARY OF HOURLY VALTRS}

\begin{tabular}{|c|c|c|c|c|c|c|c|c|c|c|c|c|}
\hline \multirow[b]{2}{*}{ MEAN } & \multicolumn{4}{|c|}{ PR IMPRY TEMP } & \multicolumn{4}{|c|}{ SDCONDARY TEMP } & \multicolumn{2}{|c|}{ PR IMPRY HUM } & \multicolumn{2}{|c|}{ SDCONDARY HUM } \\
\hline & 65.4 & ${ }^{\circ} \mathrm{F}$ & 18.6 & ${ }^{\circ} \mathrm{C}$ & 65.5 & ${ }^{\circ} \mathrm{F}$ & 18.6 & ${ }^{\circ} \mathrm{C}$ & 46.0 & $B \mathrm{PH}$ & 43.1 & SRH \\
\hline MIN & 64.6 & ${ }^{\circ} \mathrm{F}$ & 18.1 & ${ }^{\circ} \mathrm{C}$ & 64.7 & ${ }^{\circ} \mathrm{F}$ & 18.2 & ${ }^{\circ} \mathrm{C}$ & 41.3 & $\mathrm{SPH}$ & 38.1 & IFH \\
\hline $\operatorname{mix}$ & 67.2 & "F & 19.6 & ${ }^{\circ} \mathrm{C}$ & 67,3 & ${ }^{\circ} \mathrm{F}$ & 19.6 & ${ }^{\circ} \mathrm{C}$ & 61.9 & $\mathrm{BFH}$ & 61.1 & IFH \\
\hline SD & 0.47 & & 0.26 & & 0.48 & & 0.27 & & 1,87 & & 2.03 & \\
\hline SE & 0.02 & & 0.01 & & 0.03 & & 0.01 & & 0.10 & & 0.11 & \\
\hline N SAMPLES & 367 & & & & 367 & & & & 367 & & 367 & \\
\hline
\end{tabular}

EIRST DRY $03 / 12 / 13$

TAST DAY $03 / 27 / 13$

N DAYS 16 
TABLE 1

INDIVIDUAL DERMAL SCORES

PAGE 1

\begin{tabular}{|c|c|c|c|c|c|c|c|c|c|c|c|c|c|c|c|c|}
\hline \multirow[b]{3}{*}{ Animal } & \multirow{3}{*}{$\begin{array}{l}\text { erial: } \\
\text { Site: } \\
\text { Sex }\end{array}$} & \multicolumn{15}{|c|}{$\begin{array}{l}\text { JP-8 (Baseline fuel), Occluded } \\
0.5 \mathrm{~mL} / \mathrm{Site}\end{array}$} \\
\hline & & \multirow[b]{2}{*}{ Site } & \multicolumn{7}{|c|}{ Erythema } & \multicolumn{7}{|c|}{ Edema } \\
\hline & & & $0.5-1 \mathrm{H}$ & $24 \mathrm{H}$ & $48 \mathrm{H}$ & $72 \mathrm{H}$ & $4 \mathrm{D}$ & $7 \mathrm{D}$ & $14 \mathrm{D}$ & $0.5-1 \mathrm{H}$ & $24 \mathrm{H}$ & $48 \mathrm{H}$ & $72 \mathrm{H}$ & $4 \mathrm{D}$ & $7 \mathrm{D}$ & $14 \mathrm{D}$ \\
\hline 9855 & $\mathrm{M}$ & $\mathrm{A}$ & 1 & 2 & 2 & 2 & 2 & 1 & 1 & 0 & 3 & 3 & 3 & 2 & 1 & 0 \\
\hline 9852 & M & E & 2 & 2 & 2 & 2 & 2 & 2 & $2 d$ & 0 & 0 & 0 & 0 & 1 & 1 & 1 \\
\hline 9847 & M & D & 1 & 1 & 2 & 1 & 1 & 2 & ld & 0 & 0 & 0 & 0 & 0 & 1 & 0 \\
\hline
\end{tabular}

PII Calculated Using Test Periods: $1 \mathrm{H}, 24 \mathrm{H}, 48 \mathrm{H}, 72 \mathrm{H}$

Primary Irritation Index $(\mathrm{PII})=(4+5+6+5) / 12+(0+3+3+3) / 12$

$\mathrm{PII}=20 / 12+9 / 12$

$\mathrm{PII}=1.7+0.8$

$\mathrm{PII}=2.5=\quad$ Moderately Initating

$\mathrm{M}=$ Male; $\mathrm{H}=$ Hours; $\mathrm{D}=$ Day; $\mathrm{d}=$ Desquamation

Site Locations: Head

$\begin{array}{ll}\text { A } & \text { D } \\ \text { B } & \text { E } \\ \text { C } & \text { F }\end{array}$

Tail 
TABLE 1

INDIVIDUAL DERMAL SCORFS

PAge 2

\begin{tabular}{|c|c|c|c|c|c|c|c|c|c|c|c|c|c|c|c|c|}
\hline \multirow[b]{3}{*}{ Animal } & \multirow[t]{3}{*}{$\begin{array}{l}\text { lerial: } \\
\text { Site: }\end{array}$} & \multicolumn{15}{|c|}{$\begin{array}{l}\text { JP-8 (Baseline fuel), Semi-occluded } \\
0.5 \mathrm{~mL} / \text { Site }\end{array}$} \\
\hline & & \multirow[b]{2}{*}{ Site } & \multicolumn{7}{|c|}{ Erythema } & \multicolumn{7}{|c|}{ Edema } \\
\hline & & & $0.5-1 \mathrm{H}$ & $24 \mathrm{H}$ & $48 \mathrm{H}$ & $72 \mathrm{H}$ & $4 \mathrm{D}$ & $7 \mathrm{D}$ & $14 \mathrm{D}$ & $0.5-1 \mathrm{H}$ & $24 \mathrm{H}$ & $48 \mathrm{H}$ & $72 \mathrm{H}$ & $4 \mathrm{D}$ & $7 \mathrm{D}$ & $14 \mathrm{D}$ \\
\hline 9859 & M & $\mathrm{C}$ & 1 & 1 & 1 & 1 & 1 & 0 & 0 & 0 & 0 & 0 & 0 & 0 & 0 & 0 \\
\hline 7509 & M & B & 0 & 1 & 2 & 2 & 2 & 1d & $2 d$ & 0 & 0 & 1 & 0 & 1 & 0 & 0 \\
\hline 7510 & $\mathrm{M}$ & $\mathrm{A}$ & 0 & 1 & 1 & 1 & 1 & 1 & 1 & 0 & 0 & 0 & 0 & 2 & 0 & 0 \\
\hline
\end{tabular}

PII Calculated Using Test Periods: $1 \mathrm{H}, 24 \mathrm{H}, 48 \mathrm{H}, 72 \mathrm{H}$

Primary Irritation Index $(\mathrm{PII})=(1+3+4+4) / 12+(0+0+1+0) / 12$

$\mathrm{PII}=12 / 12+1 / 12$

$\mathrm{PII}=1.0+0.1$

PII $=1.1=\quad$ Slightly Irritating

$\mathrm{M}=$ Male; $\mathrm{H}=$ Hours; $\mathrm{D}=$ Day; $\mathrm{d}=$ Desquamation

Site Locations: Head

\begin{tabular}{ll} 
A & D \\
B & E \\
C & F \\
\multicolumn{2}{c}{ Tail }
\end{tabular} 
TABLE 1

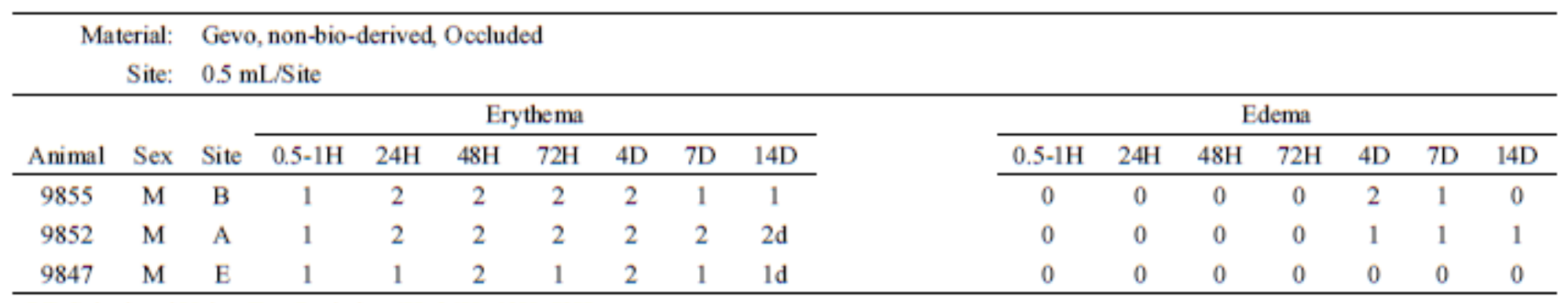

PII Calculated Using Test Periods: $1 \mathrm{H}, 24 \mathrm{H}, 48 \mathrm{H}, 72 \mathrm{H}$

Primary Irritation Index $(\mathrm{PII})=(3+5+6+5) / 12+(0+0+0+0) / 12$

$\mathrm{PII}=19 / 12+0 / 12$

$\mathrm{PII}=1.6+0.0$

PII $=1.6=\quad$ Slightly Irritating

$\mathrm{M}=$ Male; $\mathrm{H}=$ Hours; $\mathrm{D}=$ Day; $\mathrm{d}=$ Desquamation

\begin{tabular}{lll}
\hline Site Locations: & \multicolumn{2}{c}{ Head } \\
& A & D \\
& B & E \\
& C & F \\
& \multicolumn{2}{c}{ Tail }
\end{tabular}


TABLE 1

INDIVIDUAL DERMAL SCORES

PAge 4

\begin{tabular}{|c|c|c|c|c|c|c|c|c|c|c|c|c|c|c|c|c|}
\hline \multicolumn{2}{|c|}{$\begin{array}{r}\text { Material: } \\
\text { Site: }\end{array}$} & \multicolumn{15}{|c|}{$\begin{array}{l}\text { Gevo, non-bio-derived, Semi-occluded } \\
0.5 \mathrm{~mL} / \mathrm{Site}\end{array}$} \\
\hline \multirow[b]{2}{*}{ Animal } & \multirow[b]{2}{*}{ Sex } & \multirow[b]{2}{*}{ Site } & \multicolumn{7}{|c|}{ Erythema } & \multicolumn{7}{|c|}{ Edema } \\
\hline & & & $0.5-1 \mathrm{H}$ & $24 \mathrm{H}$ & $48 \mathrm{H}$ & $72 \mathrm{H}$ & $4 \mathrm{D}$ & $7 \mathrm{D}$ & $14 \mathrm{D}$ & $0.5-1 \mathrm{H}$ & $24 \mathrm{H}$ & $48 \mathrm{H}$ & $72 \mathrm{H}$ & $4 \mathrm{D}$ & $7 \mathrm{D}$ & $14 \mathrm{D}$ \\
\hline 9859 & $\mathrm{M}$ & $\mathrm{D}$ & 1 & 1 & 1 & 1 & 1 & 1 & $1 d$ & 0 & 0 & 0 & 0 & 0 & 0 & 0 \\
\hline 7509 & $\mathrm{M}$ & $\mathrm{C}$ & 0 & 1 & 2 & 2 & 2 & ld & ld & 0 & 0 & 0 & 0 & 0 & 0 & 0 \\
\hline 7510 & $\mathrm{M}$ & B & 0 & 1 & 1 & 1 & 1 & 0 & 1 & 0 & 0 & 0 & 0 & 0 & 0 & 0 \\
\hline
\end{tabular}

PII Calculated Using Test Periods: $1 \mathrm{H}, 24 \mathrm{H}, 48 \mathrm{H}, 72 \mathrm{H}$

Primary Irritation Index (PII) $=(1+3+4+4) / 12+(0+0+0+0) / 12$

$\mathrm{PII}=12 / 12+0 / 12$

$\mathrm{PII}=1.0+0.0$

PII $=1.0=\quad$ Slightly Irritating

$\mathrm{M}=$ Male; $\mathrm{H}=$ Hours; $\mathrm{D}=$ Day; $\mathrm{d}=$ Desquamation

Site Locations:

$$
\begin{array}{ll}
\multicolumn{2}{c}{\text { Head }} \\
\mathrm{A} & \mathrm{D} \\
\mathrm{B} & \mathrm{E} \\
\mathrm{C} & \mathrm{F} \\
\multicolumn{2}{c}{\text { Tail }}
\end{array}
$$


TABLE 1

INDIVIDUAL DERMAL SCORES

Page 5

\begin{tabular}{|c|c|c|c|c|c|c|c|c|c|c|c|c|c|c|c|c|}
\hline \multirow[b]{3}{*}{ Animal } & \multirow[t]{3}{*}{$\begin{array}{l}\text { terial: } \\
\text { Site: }\end{array}$} & \multicolumn{15}{|c|}{$\begin{array}{l}\text { Gevo, bio-derived, Occluded } \\
0.5 \mathrm{~mL} / \mathrm{Site}\end{array}$} \\
\hline & & \multirow[b]{2}{*}{ Site } & \multicolumn{7}{|c|}{ Erythema } & \multicolumn{7}{|c|}{ Edema } \\
\hline & & & $0.5-1 \mathrm{H}$ & $24 \mathrm{H}$ & $48 \mathrm{H}$ & $72 \mathrm{H}$ & $4 \mathrm{D}$ & $7 \mathrm{D}$ & $14 \mathrm{D}$ & $0.5-1 \mathrm{H}$ & $24 \mathrm{H}$ & $48 \mathrm{H}$ & $72 \mathrm{H}$ & $4 \mathrm{D}$ & $7 \mathrm{D}$ & $14 \mathrm{D}$ \\
\hline 9855 & $\mathrm{M}$ & $\mathrm{C}$ & 1 & 2 & 2 & 2 & 2 & 1 & 1 & 0 & 3 & 2 & 0 & 1 & 0 & 0 \\
\hline 9852 & M & B & 1 & 2 & 2 & 2 & 2 & 2 & $2 d$ & 0 & 0 & 0 & 0 & 1 & 1 & 1 \\
\hline 9847 & $M$ & $\mathrm{~A}$ & 1 & 1 & 2 & 2 & 1 & 1 & 0 & 0 & 1 & 1 & 1 & 1 & 0 & 0 \\
\hline
\end{tabular}

PII Calculated Using Test Periods: $1 \mathrm{H}, 24 \mathrm{H}, 48 \mathrm{H}, 72 \mathrm{H}$

Primary Irritation Index $(\mathrm{PII})=(3+5+6+6) / 12+(0+4+3+1) / 12$

$\mathrm{PII}=20 / 12+8 / 12$

$\mathrm{PII}=1.7+0.7$

PII $=2.4=\quad$ Moderately Initating

$\mathrm{M}=$ Male; $\mathrm{H}=$ Hours; $\mathrm{D}=$ Day; $\mathrm{d}=$ Desquamation

\begin{tabular}{lll}
\hline Site Locations: & \multicolumn{2}{c}{ Head } \\
& A & D \\
& B & E \\
& C & F \\
& \multicolumn{2}{c}{ Tail }
\end{tabular}


TABLE 1

\begin{tabular}{|c|c|c|c|c|c|c|c|c|c|c|c|c|c|c|c|c|}
\hline \multirow[b]{3}{*}{ Animal } & \multirow{3}{*}{$\begin{array}{r}\text { terial: } \\
\text { Site: } \\
\text { Sex }\end{array}$} & \multicolumn{15}{|c|}{$\begin{array}{l}\text { Gevo, bio-derived, Semi-occluded } \\
0.5 \mathrm{~mL} / \mathrm{Site}\end{array}$} \\
\hline & & \multirow[b]{2}{*}{ Site } & \multicolumn{7}{|c|}{ Erythema } & \multicolumn{7}{|c|}{ Edema } \\
\hline & & & $0.5-1 \mathrm{H}$ & $24 \mathrm{H}$ & $48 \mathrm{H}$ & $72 \mathrm{H}$ & $4 \mathrm{D}$ & $7 \mathrm{D}$ & $14 \mathrm{D}$ & $0.5-1 \mathrm{H}$ & $24 \mathrm{H}$ & $48 \mathrm{H}$ & $72 \mathrm{H}$ & $4 \mathrm{D}$ & $7 \mathrm{D}$ & $14 \mathrm{D}$ \\
\hline 9859 & $\mathrm{M}$ & $\mathrm{E}$ & 1 & 1 & 1 & 1 & 1 & 1 & 0 & 0 & 0 & 0 & 0 & 0 & 0 & 0 \\
\hline 7509 & $\mathrm{M}$ & D & 1 & 1 & 1 & 2 & 2 & 1 & ld & 0 & 0 & 0 & 0 & 0 & 0 & 0 \\
\hline 7510 & $\mathrm{M}$ & $\mathrm{C}$ & 0 & 1 & 1 & 1 & 1 & 0 & 0 & 0 & 0 & 0 & 0 & 0 & 0 & 0 \\
\hline
\end{tabular}

PII Calculated Using Test Periods: $1 \mathrm{H}, 24 \mathrm{H}, 48 \mathrm{H}, 72 \mathrm{H}$

Primary Irritation Index (PII) $=(2+3+3+4) / 12+(0+0+0+0) / 12$

$$
\begin{aligned}
& \mathrm{PII}=12 / 12+0 / 12 \\
& \mathrm{PII}=1.0+0.0 \\
& \mathrm{PII}=1.0=\quad \text { Slightly Irritating }
\end{aligned}
$$


TABLE 1

\begin{tabular}{|c|c|c|c|c|c|c|c|c|c|c|c|c|c|c|c|c|}
\hline \multirow[b]{3}{*}{ Animal } & \multirow[t]{3}{*}{$\begin{array}{l}\text { terial: } \\
\text { Site: }\end{array}$} & \multicolumn{15}{|c|}{$\begin{array}{l}\text { Swedish Biofuel (Original), Occluded } \\
0.5 \mathrm{~mL} / \mathrm{Site}\end{array}$} \\
\hline & & \multirow[b]{2}{*}{ Site } & \multicolumn{7}{|c|}{ Erythema } & \multicolumn{7}{|c|}{ Edema } \\
\hline & & & $0.5-1 \mathrm{H}$ & $24 \mathrm{H}$ & $48 \mathrm{H}$ & $72 \mathrm{H}$ & $4 \mathrm{D}$ & $7 \mathrm{D}$ & $14 \mathrm{D}$ & $0.5-1 \mathrm{H}$ & $24 \mathrm{H}$ & $48 \mathrm{H}$ & $72 \mathrm{H}$ & $4 \mathrm{D}$ & $7 \mathrm{D}$ & $14 \mathrm{D}$ \\
\hline 9855 & $\mathrm{M}$ & $\mathrm{D}$ & 1 & 1 & 1 & 2 & 2 & 2 & 1 & 0 & 2 & 2 & 1 & 2 & 1 & 0 \\
\hline 9852 & M & $\mathrm{C}$ & 2 & 2 & 2 & 2 & 2 & 2 & $2 d$ & 0 & 0 & 0 & 0 & 1 & 1 & 1 \\
\hline 9847 & M & B & 1 & 2 & 2 & 1 & 2 & 2 & $2 d$ & 0 & 1 & 1 & 1 & 1 & 1 & 1 \\
\hline
\end{tabular}

PII Calculated Using Test Periods: $1 \mathrm{H}, 24 \mathrm{H}, 48 \mathrm{H}, 72 \mathrm{H}$

Primary Irritation Index $(\mathrm{PII})=(4+5+5+5) / 12+(0+3+3+2) / 12$

$\mathrm{PII}=19 / 12+8 / 12$

$\mathrm{PII}=1.6+0.7$

PII $=2.3=$ Moderately Initating

$\mathrm{M}=$ Male; $\mathrm{H}=$ Hours; $\mathrm{D}=$ Day; $\mathrm{d}=$ Desquamation

\begin{tabular}{lll}
\hline Site Locations: & \multicolumn{2}{c}{ Head } \\
& A & D \\
& B & E \\
& C & F \\
& \multicolumn{2}{c}{ Tail }
\end{tabular}


TABLE 1

INDIVIDUAL DERMAL SCORES

PAGE 8

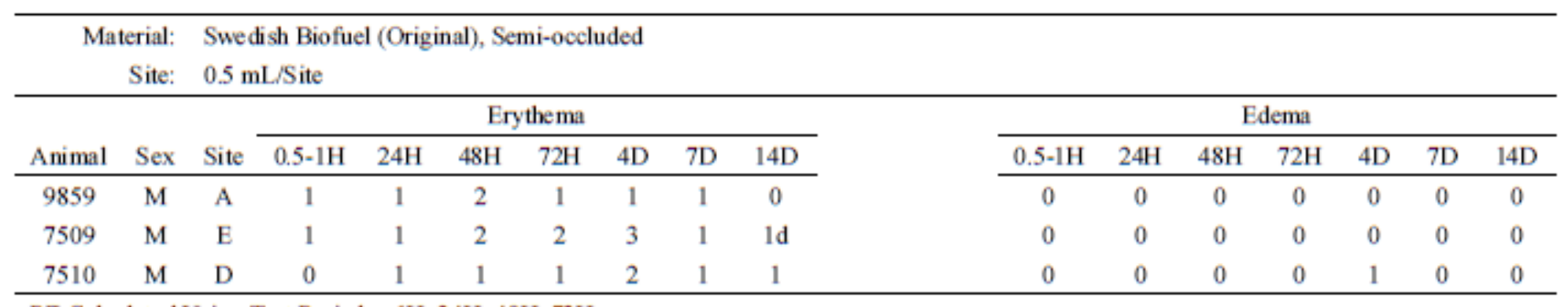

PII Calculated Using Test Periods: $1 \mathrm{H}, 24 \mathrm{H}, 48 \mathrm{H}, 72 \mathrm{H}$

Primary Irritation Index $(\mathrm{PII})=(2+3+5+4) / 12+(0+0+0+0) / 12$

$\mathrm{PII}=14 / 12+0 / 12$

$\mathrm{PII}=1.2+0.0$

PII $=1.2=\quad$ Slightly Irritating

$\mathrm{M}=$ Male; $\mathrm{H}=$ Hours; $\mathrm{D}=$ Day; $\mathrm{d}=$ Desquamation

Site Locations: Head

$\begin{array}{ll}\text { A } & \text { D } \\ \text { B } & \text { E } \\ \text { C } & \text { F }\end{array}$

Tail 
TABLE 1

INDIVIDUAL DERMAL SCORES

PAGE 9

\begin{tabular}{|c|c|c|c|c|c|c|c|c|c|c|c|c|c|c|c|c|}
\hline \multicolumn{2}{|c|}{$\begin{array}{r}\text { Material: } \\
\text { Site: }\end{array}$} & \multicolumn{15}{|c|}{$\begin{array}{l}\text { Swedish Biofuel (Current), Occluded } \\
0.5 \mathrm{~mL} / \mathrm{Site}\end{array}$} \\
\hline \multirow[b]{2}{*}{ Animal } & \multirow[b]{2}{*}{ Sex } & \multirow[b]{2}{*}{ Site } & \multicolumn{7}{|c|}{$\begin{array}{ll}\text { Erythema } \\
\end{array}$} & \multicolumn{7}{|c|}{ Edema } \\
\hline & & & $0.5-1 \mathrm{H}$ & $24 \mathrm{H}$ & $48 \mathrm{H}$ & $72 \mathrm{H}$ & $4 \mathrm{D}$ & $7 \mathrm{D}$ & $14 \mathrm{D}$ & $0.5-1 \mathrm{H}$ & $24 \mathrm{H}$ & $48 \mathrm{H}$ & $72 \mathrm{H}$ & $4 \mathrm{D}$ & $7 \mathrm{D}$ & $14 \mathrm{D}$ \\
\hline 9855 & $\mathrm{M}$ & $\mathrm{E}$ & 1 & 2 & 2 & 2 & 2 & 2 & 2 & 0 & 3 & 2 & 0 & 1 & 2 & 1 \\
\hline 9852 & M & $\mathrm{D}$ & 1 & 2 & 2 & 2 & 2 & 2 & $2 d$ & 0 & 0 & 0 & 0 & 1 & 1 & 1 \\
\hline 9847 & M & $\mathrm{C}$ & 1 & 2 & 2 & 2 & 2 & 2 & $2 d$ & 0 & 0 & 0 & 0 & 0 & 0 & 1 \\
\hline
\end{tabular}

PII Calculated Using Test Periods: $1 \mathrm{H}, 24 \mathrm{H}, 48 \mathrm{H}, 72 \mathrm{H}$

Primary Irritation Index $(\mathrm{PII})=(3+6+6+6) / 12+(0+3+2+0) / 12$

$\mathrm{PII}=21 / 12+5 / 12$

PII $=1.8+0.4$

PII $=2.2=$ Moderately Irritating

$\mathrm{M}=$ Male; $\mathrm{H}=$ Hours; $\mathrm{D}=$ Day; $\mathrm{d}=$ Desquamation

Site Locations: Head

\begin{tabular}{ll} 
A & D \\
B & E \\
C & F \\
\multicolumn{2}{c}{ Tail }
\end{tabular}


TABLE 1

INDIVIDUAL DERMAL SCORES

PAGE 10

\begin{tabular}{|c|c|c|c|c|c|c|c|c|c|c|c|c|c|c|c|c|}
\hline \multirow[b]{3}{*}{ Animal } & \multirow{3}{*}{$\begin{array}{r}\text { terial: } \\
\text { Site: } \\
\text { Sex }\end{array}$} & \multicolumn{15}{|c|}{$\begin{array}{l}\text { Swedish Biofuel (Current), Semi-occluded } \\
0.5 \mathrm{~mL} / \text { Site }\end{array}$} \\
\hline & & \multirow[b]{2}{*}{ Site } & \multicolumn{7}{|c|}{ Erythema } & \multicolumn{7}{|c|}{ Edema } \\
\hline & & & $0.5-1 \mathrm{H}$ & $24 \mathrm{H}$ & $48 \mathrm{H}$ & $72 \mathrm{H}$ & $4 \mathrm{D}$ & $7 \mathrm{D}$ & $14 \mathrm{D}$ & $0.5-1 \mathrm{H}$ & $24 \mathrm{H}$ & $48 \mathrm{H}$ & $72 \mathrm{H}$ & $4 \mathrm{D}$ & $7 \mathrm{D}$ & $14 \mathrm{D}$ \\
\hline 9859 & $\mathrm{M}$ & $\mathrm{B}$ & 1 & 1 & 2 & 1 & 1 & 2 & $1 d$ & 0 & 1 & 0 & 0 & 0 & 0 & 0 \\
\hline 7509 & $\mathrm{M}$ & $\mathrm{A}$ & 0 & 1 & 2 & 2 & 2 & ld & Id & 0 & 0 & 1 & 0 & 1 & 0 & 0 \\
\hline 7510 & $\mathrm{M}$ & E & 0 & 1 & 1 & 1 & 1 & 1 & 1 & 0 & 0 & 0 & 0 & 1 & 0 & 0 \\
\hline
\end{tabular}

PII Calculated Using Test Periods: $1 \mathrm{H}, 24 \mathrm{H}, 48 \mathrm{H}, 72 \mathrm{H}$

Primary Irritation Index $(\mathrm{PII})=(1+3+5+4) / 12+(0+1+1+0) / 12$

$\mathrm{PII}=13 / 12+2 / 12$

$\mathrm{PII}=1.1+0.2$

PII $=1.3=$ Slightly Irritating

$\mathrm{M}=$ Male; $\mathrm{H}=$ Hours; $\mathrm{D}=$ Day; $\mathrm{d}=$ Desquamation

Site Locations: Head

$\begin{array}{ll}\text { A } & \text { D } \\ \text { B } & \text { E } \\ \text { C } & \text { F }\end{array}$

Tail 


\section{APPENDIX G. COMPLIANCE, REPORT APPROVAL AND QUALITY ASSURANCE STATEMENTS}

WIL-773003

Four Bio-Based Jet Fuels

The Henry M. Jackson Foundation

\section{COMPLiance STATEMENT}

This study, designated WIL-773003, was conducted in compliance with the United States EPA Good Laboratory Practices (40 CFR 792), 18 September 1989; WIL Research's SOPs; and the protocol as approved by the Sponsor with the following exception. Analytical confirmation of the concentration, purity, homogeneity, and stability of the test substances was not supplied by the Sponsor and was not conducted as part of this study. Due to the screening nature of this study and the inherent stability of jet fuels, this exception did not negatively impact the quality or integrity of the data or interpretation of the results of the study.
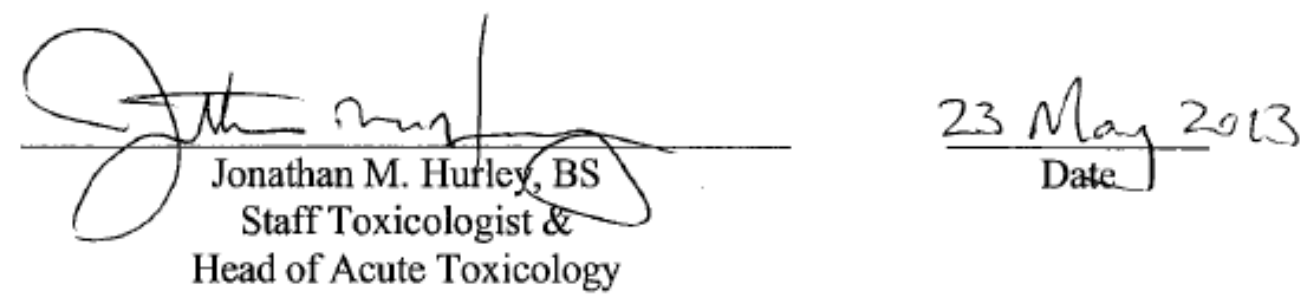


\section{REPORT REVIEW AND APPROVAL}

Report Authored and Approved By:

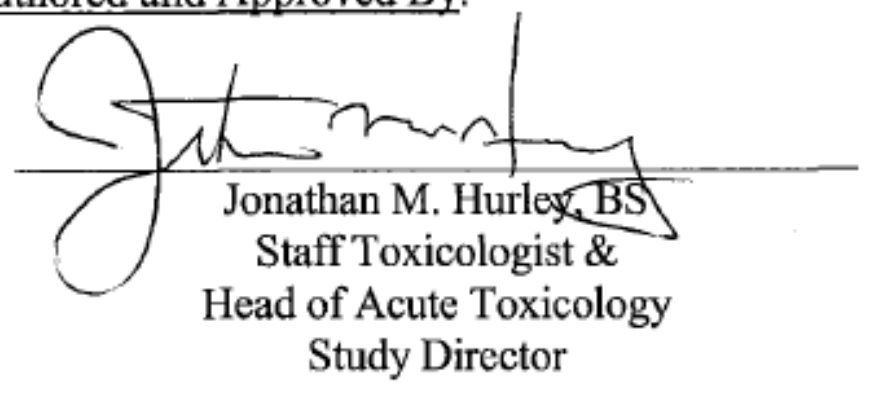

$$
\frac{23 \text { Manzois }}{\text { Date }}
$$

Report Prepared By:
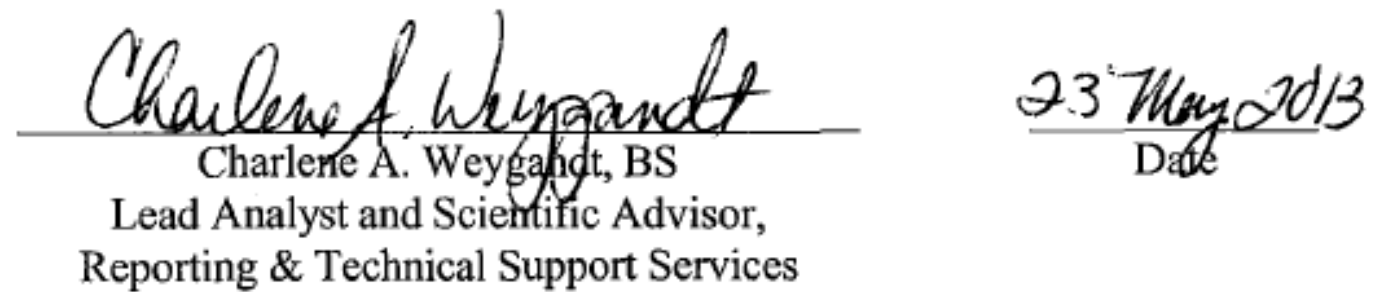

Reporting \& Technical Support Services

Reviewed By:

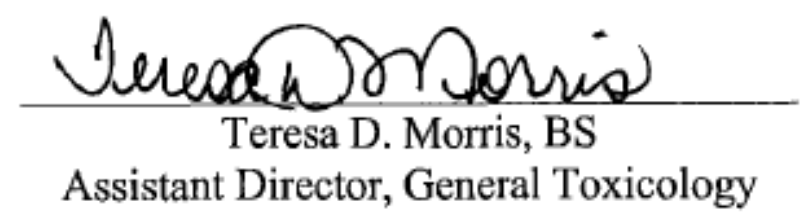

$\frac{23 \operatorname{may}_{\text {Date }} 2013}{2}$ 


\section{QUALITY ASSURANCE STATEMENT}

Date(s) of

Inspection(s)

15-Feb-2013

15-Feb-2013

12-Mar-2013

16-Apr-2013

17-Apr-2013

17-Apr-2013

30-Apr-2013

07-May-2013

22-May-2013
Phase Inspected

Protocol Amendment 1

Protocol

Test Substance Administration

Study Records (I-1)

Study Records (Rx-1)

Draft Report

Audited Report

Final Report
Date(s) Findings

Reported to Study

Director and

Management

15-Feb-2013

15-Feb-2013

12-Mar-2013

17-Apr-2013

17-Apr-2013

30-Apr-2013

07-May2013

22-May2013

This study was inspected in accordance with the current GLP Regulation, WIL Research's SOPs, and the Sponsor's protocol. A yearly internal facility inspection is conducted by the WIL Research Quality Assurance Department Research. A status report is submitted to management monthly.

This report accurately reflects the data generated during the study. The methods and procedures used in the study were those specified in the protocol, its amendments, and WIL Research's SOPs.
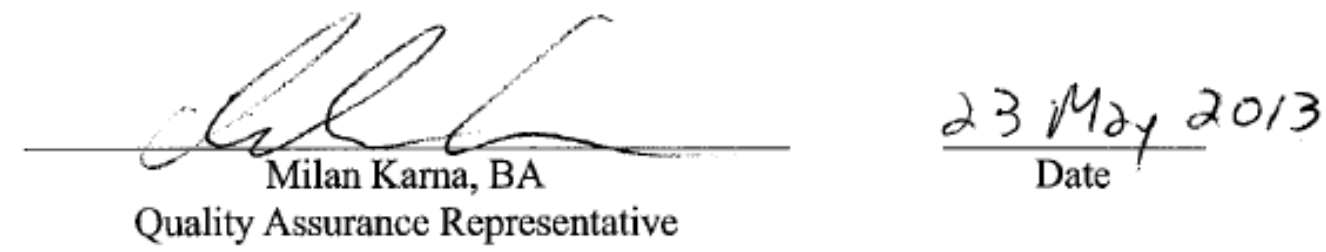


\section{LIST OF ACRONYMS}

AAALAC Association for Assessment and Accreditation of Laboratory Animal Care

AFB Air Force Base

AFRL

ATJ

Air Force Research Laboratory

AVMA American Veterinary Medical Association

bio biologically-derived

DARPA Defense Advanced Research Projects Agency

DOD Department of Defense

DTIC Defense Technical Information Center

EPA Environmental Protection Agency

GC gas chromatography

GLP Good Laboratory Practices

HJF Henry M. Jackson Foundation for the Advancement of Military Medicine

non-bio non-biologically-derived

OECD Organisation for Economic Cooperation and Development

OPPTS Office of Prevention, Pesticides and Toxic Substances

PDII Primary Dermal Irritation Index

SB synthetic JP-8

SOP standard operating procedure

SPK synthetic paraffinic kerosene

USAF U.S. Air Force 